\title{
Nanoimprint lithography: 2D or not 2D? A review
}

\author{
Helmut Schift ${ }^{1}$
}

Received: 29 January 2015/Accepted: 13 March 2015/Published online: 1 April 2015

(C) Springer-Verlag Berlin Heidelberg 2015

\begin{abstract}
Nanoimprint lithography (NIL) is more than a planar high-end technology for the patterning of wafer-like substrates. It is essentially a 3D process, because it replicates various stamp topographies by $3 \mathrm{D}$ displacement of material and takes advantage of the bending of stamps while the mold cavities are filled. But at the same time, it keeps all assets of a 2D technique being able to pattern thin masking layers like in photon- and electron-based traditional lithography. This review reports about 20 years of development of replication techniques at Paul Scherrer Institut, with a focus on 3D aspects of molding, which enable NIL to stay 2D, but at the same time enable 3D applications which are "more than Moore." As an example, the manufacturing of a demonstrator for backlighting applications based on thermally activated selective topography equilibration will be presented. This technique allows generating almost arbitrary sloped, convex and concave profiles in the same polymer film with dimensions in micro- and nanometer scale.
\end{abstract}

\section{Introduction}

Planar technology for semiconductor technology has taught us that only the surface of a silicon wafer is structured, by additive and subtractive techniques for the creation and removal of thin films or parts of it [1]. It is essentially two dimensional (2D), since the films (coatings with photoresist, metal, dielectrics layers) are thin in comparison with

Helmut Schift

helmut.schift@psi.ch

1 Laboratory for Micro- and Nanotechnology, Paul Scherrer Institut (PSI), 5232 Villigen, Switzerland the substrate, i.e., the silicon wafer. With the advent of microtechnology and micromachining deep into the substrate, the entire wafer has become integral part of the device, which is often still 2D, since the bulk silicon often constitutes a simple opening for a membrane device. An approach toward 3D is using deep reactive ion etching (DRIE) or deep X-ray lithography (DXRL, the "Li"-part of the so-called LiGA-technology), making it possible to use the silicon bulk as a mechanical sensor, clamp or optical microelements with registration [2-4]. Because these processes mainly create binary structures with ultra-high aspect ratios (HAR, width to height ratios of higher than 100:1 have been achieved), they are often named $2 \frac{1}{2} \mathrm{D}$ (2.5D) techniques. Three dimension, in contrast to this, means freeform design with undercuts, bridges, membranes, convex and concave structures, combined with vertical sidewalls. In general, $2 \frac{1}{2} \mathrm{D}$ is a term often used, when the design freedom is strongly restricted by lithographical boundary conditions, which is already given by the substrate to which a 3D structure needs to be attached. However, even advanced 3D processes have such restrictions, and are therefore "less than true 3D." Similarly, planar technologies deal with deep trenches, multiple levels, undercuts for lift-off, sidewall decoration by inclined evaporation and conformal surface atomic layer deposition (ALD), which make them truly 3D. Before starting with the description of the nanoimprint lithography (NIL) process, its 2D and 3D characteristics are summarized in Table 1, including examples.

NIL is traditionally considered as a $2 \mathrm{D}$ process, most of all, because it was first considered as an alternative to highend nanolithography, and therefore uses planar substrates and thin film technologies [9-20]. But it is essentially a 3D process, because it molds stamp topographies into a resist layer by using capillary action and squeeze flow below 


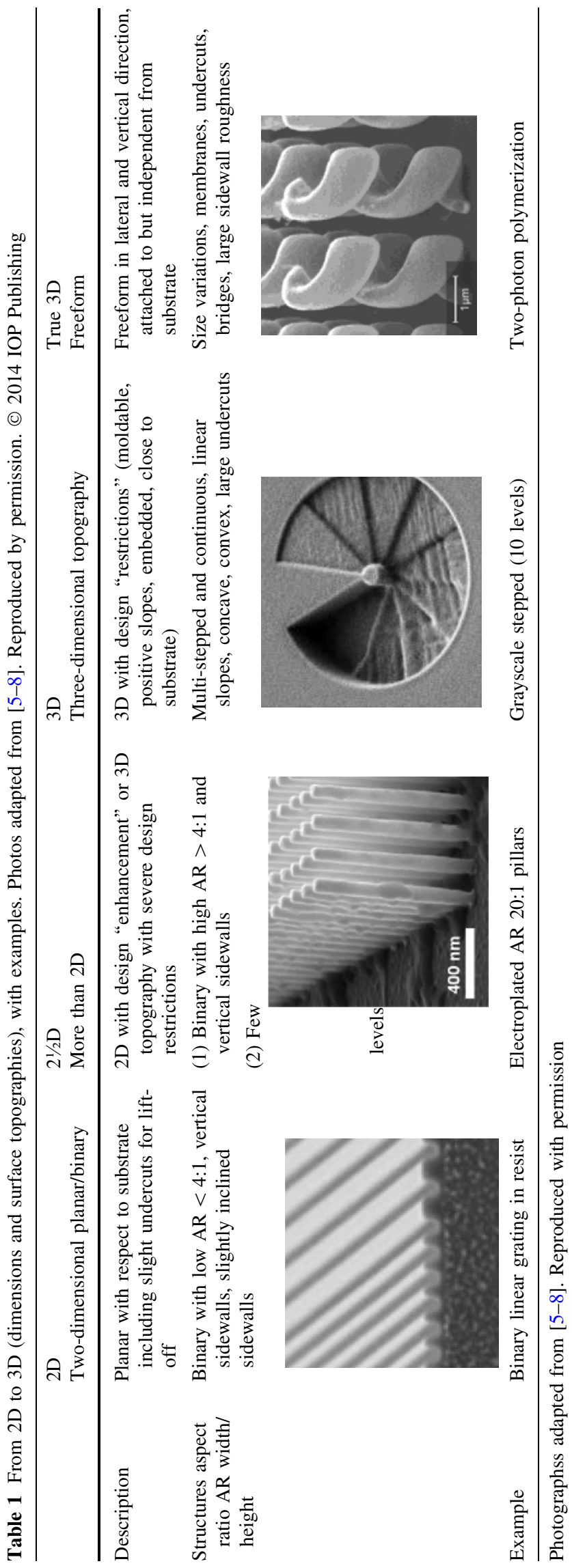

surface protrusions and into cavities of a stamp with arbitrary shape, thus creating a specific thickness contrast [2123]. This is a local displacement of material into both lateral and vertical directions, thus 3D. But at the same time, it maintains many characteristics of a $2 \mathrm{D}$ process, because it relies on a vertical movement of a stamp during molding and demolding and therefore does not allow undercuts. Also the etching of the nonzero residual layer is predominantly anisotropic in vertical direction and therefore $2 \mathrm{D}$. This is similar to the $2 \mathrm{D}$ characteristics of the shadow exposure in photolithography, where the latent image in the resist is converted into a binary profile by wet development and etching of the resist in the exposed areas, until the substrate is cleared. We can look at this characteristic from two angles: (a) the "global versus local" aspect (also called farfield and nearfield), which mainly means a distinction between the lateral extension of single cavities and entire substrates and (b) the "surface versus bulk" aspect, which means the ratio between the sizes of the structure in comparison with the total volume in close vicinity which is molded.

In the global view, i.e., for topographies over larger distances, NIL can be considered as a $2 \mathrm{D}$ technique, as long as planar substrates and stamps are used. "Planarization" is achieved by local bending of stamps which is often negligible in comparison with the structures to be molded. Even roll-to-roll (R2R) processes are still planar techniques because in the proximity of the stamp protrusions, it still behaves like a flat stamp, since the area of contact (the "nip") is not zero (i.e., a line), but extended to a few millimeters [24-29]. The difference in filling is less a 3D process but a directional one, i.e., that the pressure builds up from the side rather in a wedge-like manner than uniformly from top. Similarly, in R2R, the demolding is done by delamination, which is still planar because it starts with a minor wedge which is similar to a fully vertical movement over the entire stamp. Therefore, although many global aspects seem to be clearly $3 \mathrm{D}$, the local aspect is rather 2D. This distinction is similar to that in [30], where the levels of dimensions and dimensional effects in NIL were divided into nanoscopic $(0.1-100 \mathrm{~nm})$, sub-microscopic $(100-1000 \mathrm{~nm})$, microscopic $(1-100 \mu \mathrm{m})$ and macroscopic $(>0.1 \mathrm{~mm})$ to handling size (wafers). In [21, 31-33], these aspects of 3D with respect to size ratios are presented. Since a final structure with a specific desired shape can be achieved with a range of processes, it is particularly important to consider not only the so-called aspect ratio of structures, but also the ratio of the structures size to the underlying "connecting substrate." From experience, the distinction between thin spincoated films with some 10s of nano up to some micrometers, thin foils in the range of some 10s up to 100 s of micrometers and thick plates seems appropriate, which has much to do with the 
fact that in thermal NIL, high pressures are needed. Then, the thinning of resists down to "almost zero" residual layer is a challenge, while for thick plates, the ability of material bulk to move laterally can lead to a fast unwanted thinning of the substrate. Thin foils, in contrast to this, can be imprinted easily at the surface, but are still restricted to flow laterally over large distances. This shows that a good balance between the local and the global aspects is essential.

The aim of this paper is to demonstrate the $3 \mathrm{D}$ characteristics of the NIL process, over the entire process chain, and to emphasize where this "more than 2D" character makes NIL different from traditional lithography. It will be a review of work performed at Paul Scherrer Institut (PSI) during the last 20 years of research and development on molding processes, and will contain some unpublished data and figures which illustrate these 3D properties of NIL [30, 34]. In addition to that, some key results from other sources with relevance to 3D will be shown. As an example for 3D, the TASTE process (thermally activated selective topography equilibration) will be presented, a process which enables to fabricate 3D surface topographies using electron beam lithography (EBL) and selective thermal reflow, with a backlight device as an example. This is a process mainly used for mastering. This review is complemented by two other recent papers where two important aspects of molding have been presented, the similarities of NIL and LiGA and the description of the NIL process chains [35, 36], including the main process steps such as origination, replication and pattern transfer. A range of further $3 \mathrm{D}$ micro- and nanostructures based on NIL can be found in [37]. In the following, the toolbox approach for NIL with focus on 3D processes will be presented, followed by applications with 3D features.

\section{The 3D challenge to NIL}

\subsection{NIL process chain and toolbox}

The NIL process chain comprises the main processes such as origination, replication and pattern transfer [36, 38-40], which is often not complete if process cycles are iterated or combined with other processes. For example, stamp manufacturing may include a replication step for stamp copying and the pattern transfer may include a bonding step by reverse NIL. This becomes even more complicated if other molding processes are integrated in the toolbox of replication, e.g., replica casting and injection molding, in which a surface pattern is generated on a bulk element [36, 39 ], or microcontact printing $(\mu \mathrm{CP})$, in which an ink is transferred from the protrusions of a stamp to a surface [41, 42]. Furthermore, the toolbox of pattern transfer may contain many processes with 3D quality, e.g., if electroplating [43] is used or membranes are structured [44]. Replica molding, replica casting, and injection molding are all dealing with the bulk quality of a material, and injection molding is a typical example where 3D flow simulations are done. However, also here, it is difficult to distinguish which quality really is $3 \mathrm{D}$ in a local microscopic world and which in a global one. As long as only single processes of the toolbox have to be replaced, 3D NIL will not be a severe challenge for process development. 3D aspects, however, become prominent if the vertical movement of polymer during molding has to be managed. An overview about the NIL toolbox is given in [39]. Figure 1 shows schematics with different processes for 3D topography origination, replication and pattern transfer.

\subsection{Origination}

Origination is often performed by a lithographic process which is either a direct complement of NIL, but not applicable for high-volume, large-area manufacturing, or so complex that it is still a challenge to achieve reproducible results either within a large array of identical structures or between different exposures [45-66]. An example for the first case is EBL, and for the second case grayscale (modulated-dose) EBL with defined step heights [45-48]. In contrast to NIL, they require specific resist materials with dose-depth contrast characteristics. NIL, and in particular thermal NIL, is unique because it can pattern a range of functional materials by simple mechanical contact and 3D material displacement. Photolithography (PL) and EBL have made tremendous progress toward exposing resists to defined levels of doses with high lateral resolution, taking into account proximity effects by using sophisticated software [49]. These dose levels are transformed into height levels in appropriate wet developers, by adjusting the dose-development rate, e.g., of positive PL and EBL resists. Due to inhomogeneity in material properties or the limitations of control of the software-hardware interface (e.g., splitting a design into sub-fields), often roughness issues arise, additional to the fact that wet development is an isotropic process which leads to edge rounding. In contrast to this, 3D lithography based on two-photon absorption by direct laser writing has raised interest $[8,50]$. Also here, the roughness is not only due to process issues, but also due to discretization (data discretization, exposure in scanning or vector-mode with defined increments). Other new processes are currently explored by heated scanning probe tip-based lithography [51-53]. The first allows the creation of almost freeform structures by scanning a high-intensity voxel (above the resist's pronounced threshold of polymerization) through a negative resist, and the second by decomposing the polymer into volatile units by the heat transferred from a heated 


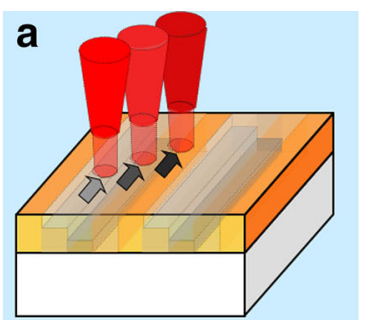

Grayscale exposure with scanned beam

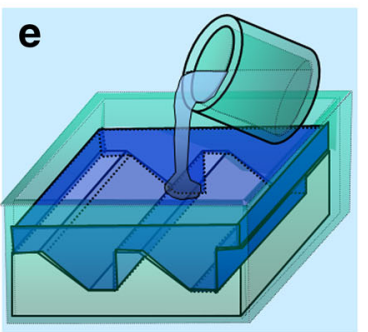

Casting of stamp copy

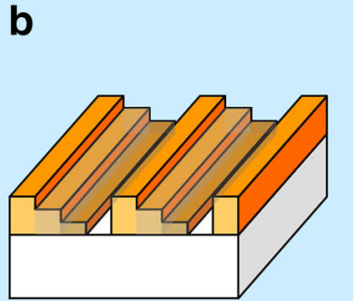

Wet development (dose selective)

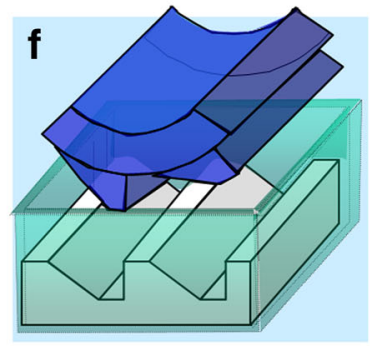

Demolding of bendable stamp

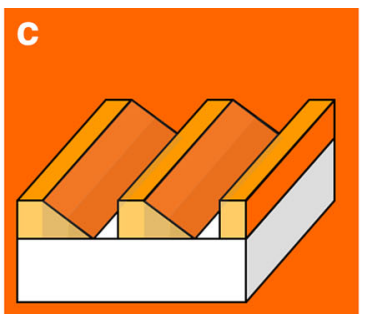

Selective thermal reflow (TASTE)

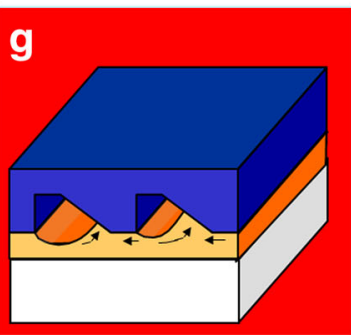

Thermal imprint (incomplete filling)

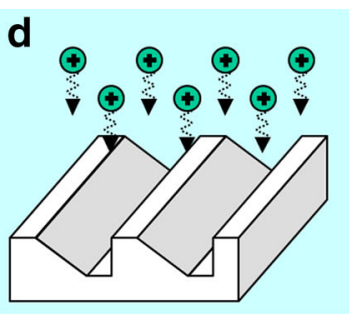

Proportional reactive ion etching

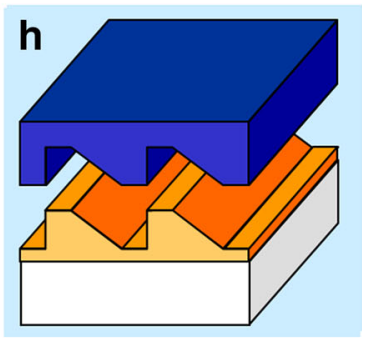

Demolding of 3D structures

Fig. 1 Schematics with different processes, a origination by dosemodulated EBL, b multilevel structures after development. Postprocessing by c sloped structures after selective thermal reflow,

d hard stamp by proportional etching and e casting of soft stamp, $\mathbf{f}$ peel demolding, $\mathbf{g}$ imprint with hard or soft stamp $\mathbf{f}$ and $\mathbf{h}$ demolding [39]

tip to the resist. Apart from this, multilevel PL using successive steps of lithography and etching is still an option for specific applications requiring only a low number of levels [54]. Vertical sidewalls are characteristic for binary patterning, but it is still a challenge to generate defined sidewall inclination or even cylindrical or spherical shapes with smooth surfaces. For this, isotropic etching processes or surface energy minimization of thermoplastic structures by thermal reflow [54-59], including strategies for selective reflow, have been developed. In Fig. 2, three examples are presented for such 3D structures based on self-limiting processes. In Fig. 3, an elongated stepped structure is transformed into a smooth slope by selective reflow [7, 6064]. As has been shown with the molded pyramids, pattern inversion is used if the desired convex shape cannot be achieved directly, here from anisotropically etched $<100>$ silicon molds with $2 \mu \mathrm{m}$ width. Similarly, concave molds with perfect spherical shape could be fabricated from isotropically etched silicon or $\mathrm{SiO}_{2}$ [65]. Then, the corresponding convex structure can be fabricated by molding too. Convex microlenses with perfect spherical shape can be directly formed from thermal reflow of thermoplastic polymer granules or box-type resist structures. However, complex structures (non-spherical, half-lenses, sloped and vertical sidewalls, as well as combinations of convex and concave structures) are difficult to achieve with such processes which use homogeneous substrate or mold materials

and fixed resist heights (starting from binary structures) [66]. Therefore, the TASTE process was developed which is based on selective thermal reflow. The capabilities of this process will be explained in the following in more detail.

TASTE is a process with many variants. It is essentially based on the generation of a localized material contrast in an originally homogeneous material, either a 3D profile after development of an exposed spincoated film or alternatively after exposure of a 3D relief which was patterned by imprint. This enables the further selective processing of the modified material while the non-modified stays unaltered [61]. The "local" process can be done by scanning exposure using EBL, the "global" process by heating the entire film up to a temperature where this part of the resist gains an enhanced ability to flow. A polymer such as poly(methyl methacrylate) (PMMA) is characterized by its molecular weight, which makes it both applicable as positive resist in EBL and also as thermoplastic material for molding. As a coincidence, the reduction in the molecular weight by exposure with typical doses of electrons used in EBL results in "two thresholds" below which the PMMA can be characterized by a distinct contrast in etching in standard wet developers such as MIBK (methyl isobutyl ketone) but also in which the glass transition temperature is lowered to such an extent that exposed polymer chains gain a mobility in which significant flow 

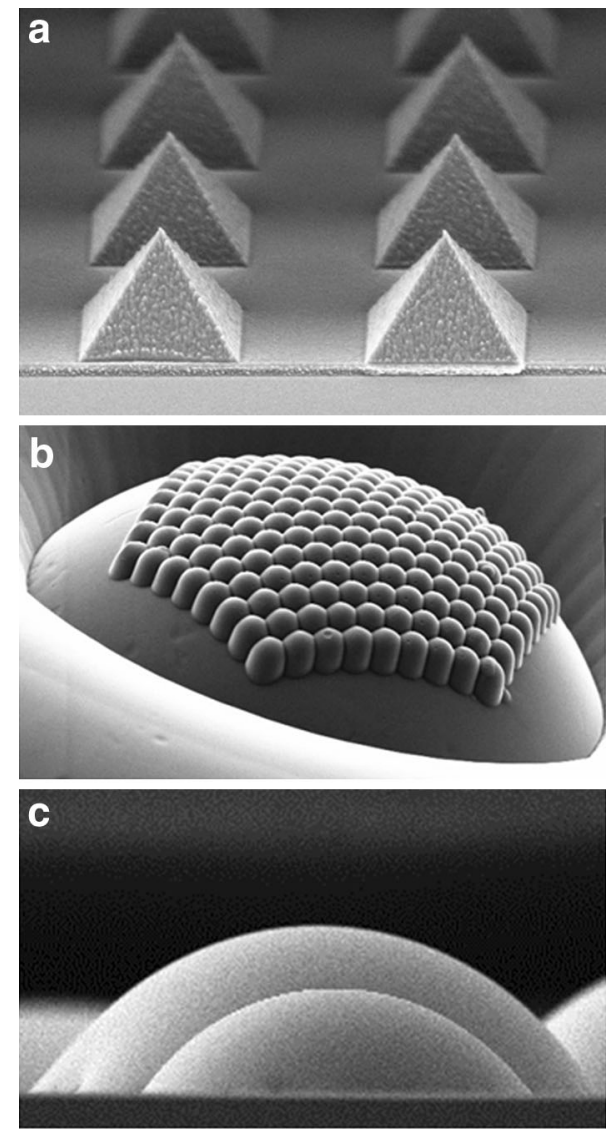

Fig. 2 SEM micrographs of 3D shapes: a pyramids ( $2 \mu \mathrm{m}$ footprint $)$ by molding of a $<100>$ silicon stamp after anisotropic etching. b Convex lenses by molding of concave cavities in a silicon oxide wafer after isotropic etching. c Convex spherical shapes by thermal reflow of PMMA granules at high temperatures $\left(180{ }^{\circ} \mathrm{C}\right)$. Photographs adapted from $[65,66]$. Reproduced by permission. (C) 2015 IOP Publishing

Fig. 3 SEM micrographs (cross sections) of 3D topographies in $1-\mu \mathrm{m}$-thick PMMA fabricated by selective thermal reflow at moderate temperatures. With different combinations of temperature and time, linear slopes with similar shapes can be achieved (red frames) [7, $60]$. Reproduced by permission. (c) 2015 Elsevier can be achieved. As can be seen in the dose-development rate-depth- $T_{\mathrm{g}}$ relation in Fig. 4 , a dose of e.g., $225 \mu \mathrm{C} / \mathrm{cm}^{2}$ leads to a reduction in the molecular weight (here number average molecular weight $M_{\mathrm{n}}$ instead of the weight average molecular weight $M_{\mathrm{w}}$ ) from $40 \mathrm{~kg} / \mathrm{mol}$ (nominal $M_{\mathrm{w}}$ $120 \mathrm{~kg} / \mathrm{mol}$ ) of the untreated material down to $7.0 \mathrm{~kg} / \mathrm{mol}$ and a reduction in the initial $T_{\mathrm{g}, \mathrm{EBL}}$ from 122 to $100{ }^{\circ} \mathrm{C}$, and for $400 \mu \mathrm{C} / \mathrm{cm}^{2}$ down to $4.3 \mathrm{~kg} / \mathrm{mol}$ and a $T_{\mathrm{g}}$ of $90{ }^{\circ} \mathrm{C}$. By choosing an initial (nominal) $M_{\mathrm{w}}$ of $120 \mathrm{~kg} / \mathrm{mol}$, a good compromise between properties needed for both EBL and NIL can found, i.e., a $M_{\mathrm{w}}$ high enough to provide sufficient contrast of unexposed and exposed resist and a $M_{\mathrm{w}}$ low enough that a low-enough viscosity of the resist during typical imprint temperatures of about $180{ }^{\circ} \mathrm{C}$ is achieved (see Fig. 5). This way, by using a $1-\mu \mathrm{m}$-thick PMMA film as an EBL resist, $225 \mu \mathrm{C} / \mathrm{cm}^{2}$ results in a removal of $200 \mathrm{~nm}$ and the second dose $400 \mu \mathrm{C} / \mathrm{cm}^{2}$ of $800 \mathrm{~nm}$, while the unexposed resist exhibits negligible dark erosion. A resist topography or pattern imprinted prior to exposure will stay unaltered in unexposed areas, while development and reflow processes can be entirely confined to areas of exposed resists. This makes it possible to provide solutions of mixed micro- and nanostructures. We can speak of thresholds, as long as contrasts are high enough, but it is evident that every process needs to be calibrated with respect to structural sizes and resolution. This is particularly important since the reflow temperature used for TASTE is typically chosen near the $T_{\mathrm{g}, \mathrm{EBL}}$ of the initial material, which represents a range of a few ${ }^{\circ} \mathrm{C}$ rather than a distinct temperature in which softening sets in (see Fig. 5). This way, since the reflow process is different from the standard reflow of spherical and cylindrical lenses to achieve minimum surfaces (which is typically near the imprint

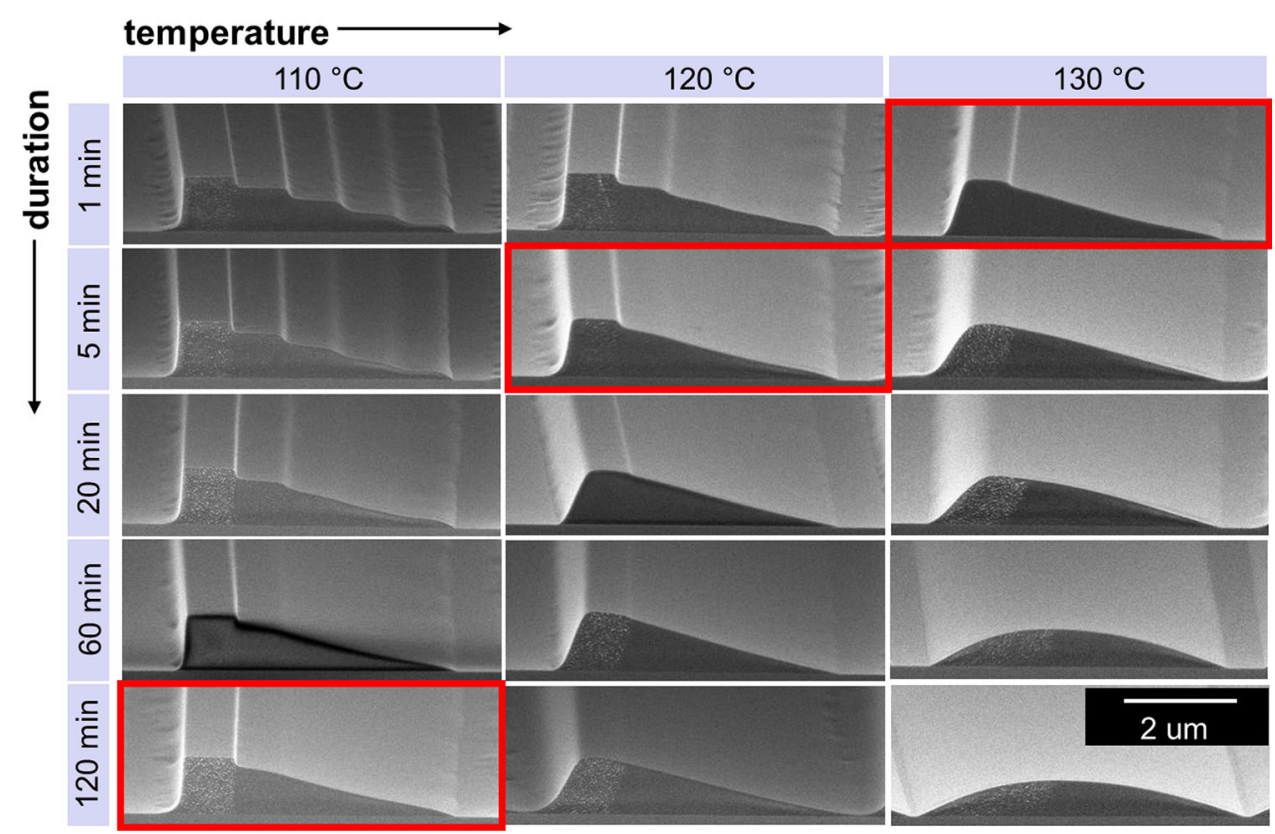




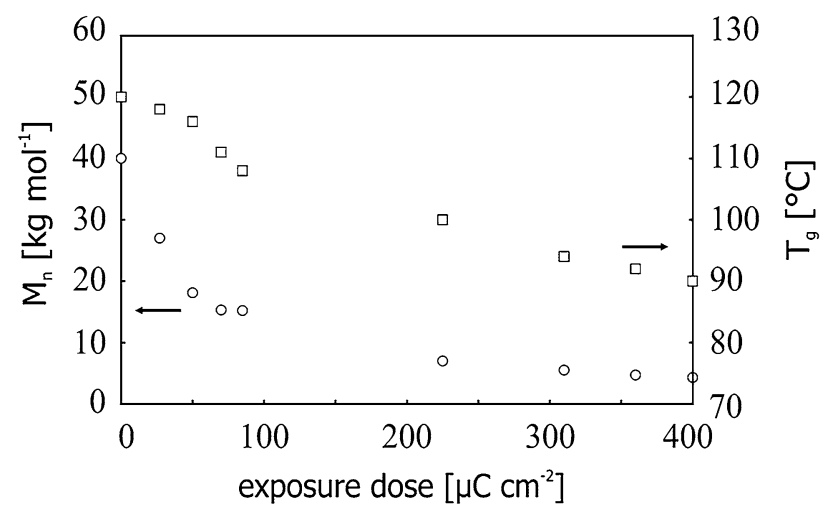

Fig. 4 Dose-development rate-depth- $T_{\mathrm{g}}$ relation: by choosing an initial $M_{\mathrm{w}}$ of $120 \mathrm{~kg} / \mathrm{mol}$, a good compromise is possible between properties needed for both EBL and NIL [61]

temperature, i.e., around $180{ }^{\circ} \mathrm{C}$ ), we will find an interdependence of both temperature and time, i.e., long reflow times will also affect unexposed areas but will result in similar shapes as higher reflow temperatures for smaller times (see Fig. 3). Thus, possibilities to optimize final structures are provided. A reduction in $T_{\mathrm{g}}$ of more than $20{ }^{\circ} \mathrm{C}$, however, even for the highest step in an EBL-exposed structure, is sufficiently large to enable selectivity.

A final word has to be said about the use of pinning. Since reflow is based on energy minimization of surfaces, convex spherical and cylindrical surfaces are favored, or in case of flat surfaces with roughness, an entirely smoothened surface. The use of pillars of the same material but high $M_{\mathrm{w}}$ (and thus $T_{\mathrm{g}}$ ) inhibits the formation of convex structures, thus resulting in a flat on top of the resist. This pillar (in Fig. 6 shown as a ridge along two steps exposed with different doses) is covered at its sidewall by the material of the steps and (provided that there is enough material to flow upwards), due to this "pinning", generates a slope starting from the corner of the flat. At the same time, a second pinning takes place at the substrate surface where the lowest step begins to flow. A staircase slope of only a few steps can thus be transformed into a continuous slope between two pinning points, provided that none of these pinning points moves and that flow is confined (i.e., within one or two steps). This "stable" case is compromised if either the unexposed pillar is able to deform or the surface near the lowest step is not pinned, i.e., in the case when it is covered by a thin residual layer of the same material and the material is able to move. In the first case, a convex crest, and in the second case, a concave depression will form. Both processes are not assuming energy minima different from convex lenses or totally equilibrated films; therefore, an "intermediate equilibration" needs to be targeted at which the reflow process is stopped. Since TASTE reflow processes can be made selectively slow in comparison with reflow aimed to form lenses, there is enough time to interrupt the process in which intermediate surface equilibration within the "envelope" of the steps is possible, thus enabling freeform surface contours. The main task is to balance the need for resolution in lateral and vertical direction, and the writing time. Here, TASTE would enable to smoothen out roughness imminent to the process and enable to balance between surface finish (which is in principle also a resolution issue) and writing time. As with the continuous slopes, a balance has then to be found to use
Fig. 5 Schematics showing the mechanical properties (storage module $\mathrm{G}^{\prime}$ ) of typical thermoplastic polymers and the dependence of their glass transition temperature $T_{\mathrm{g}}$ on the molecular weight $M_{\mathrm{w}}[62]$

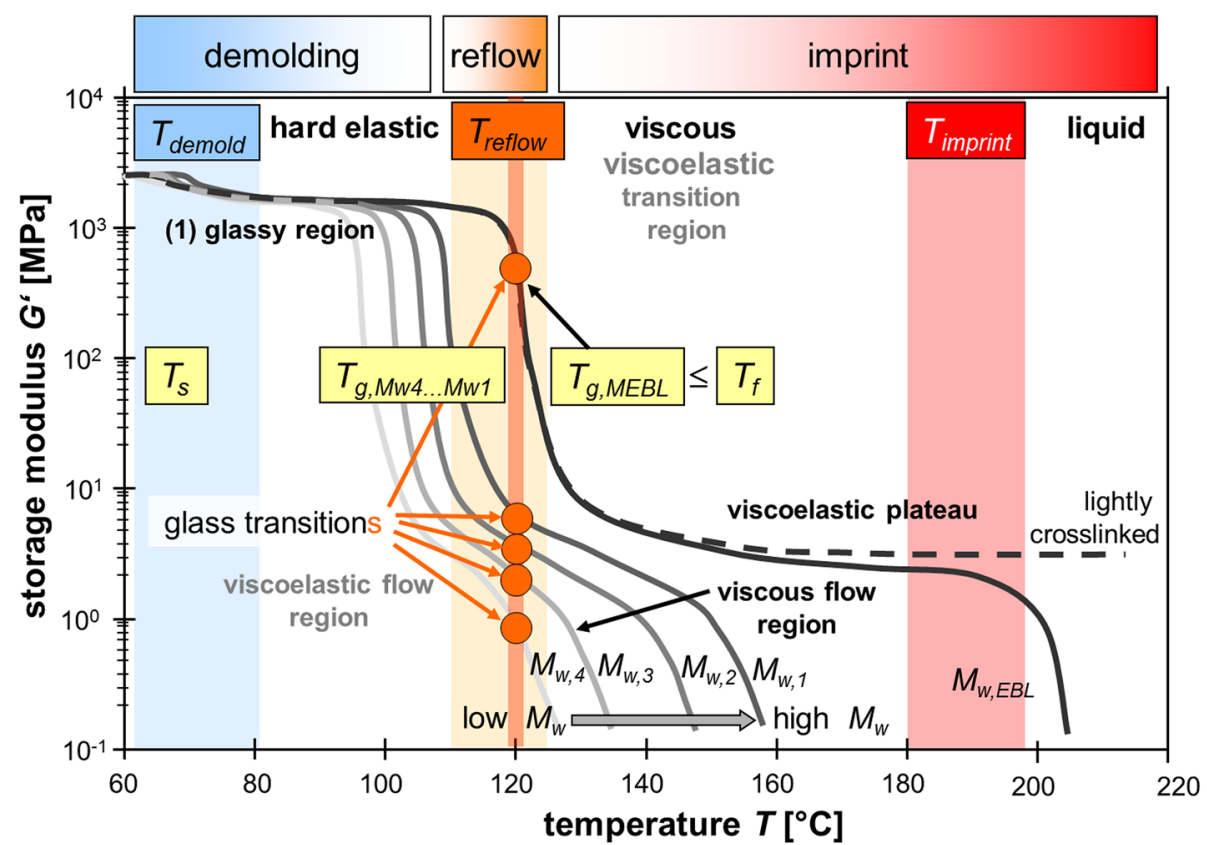


Fig. 6 Schematics with different shapes from thermal reflow of stepped structures after dose-modulated EBL, a with and $\mathbf{b}$ without window opening. $\mathbf{c}$ and $\mathbf{d}$ show slopes due to pinning at substrate, $\mathbf{d}$ and $\mathbf{f}$ concave shapes with central depression due to covered substrate, $\mathbf{c}$ and d pinning at non-exposed ridges, $\mathbf{e}$ and $\mathbf{f}$ convex crests due to moderate exposure of top ridges
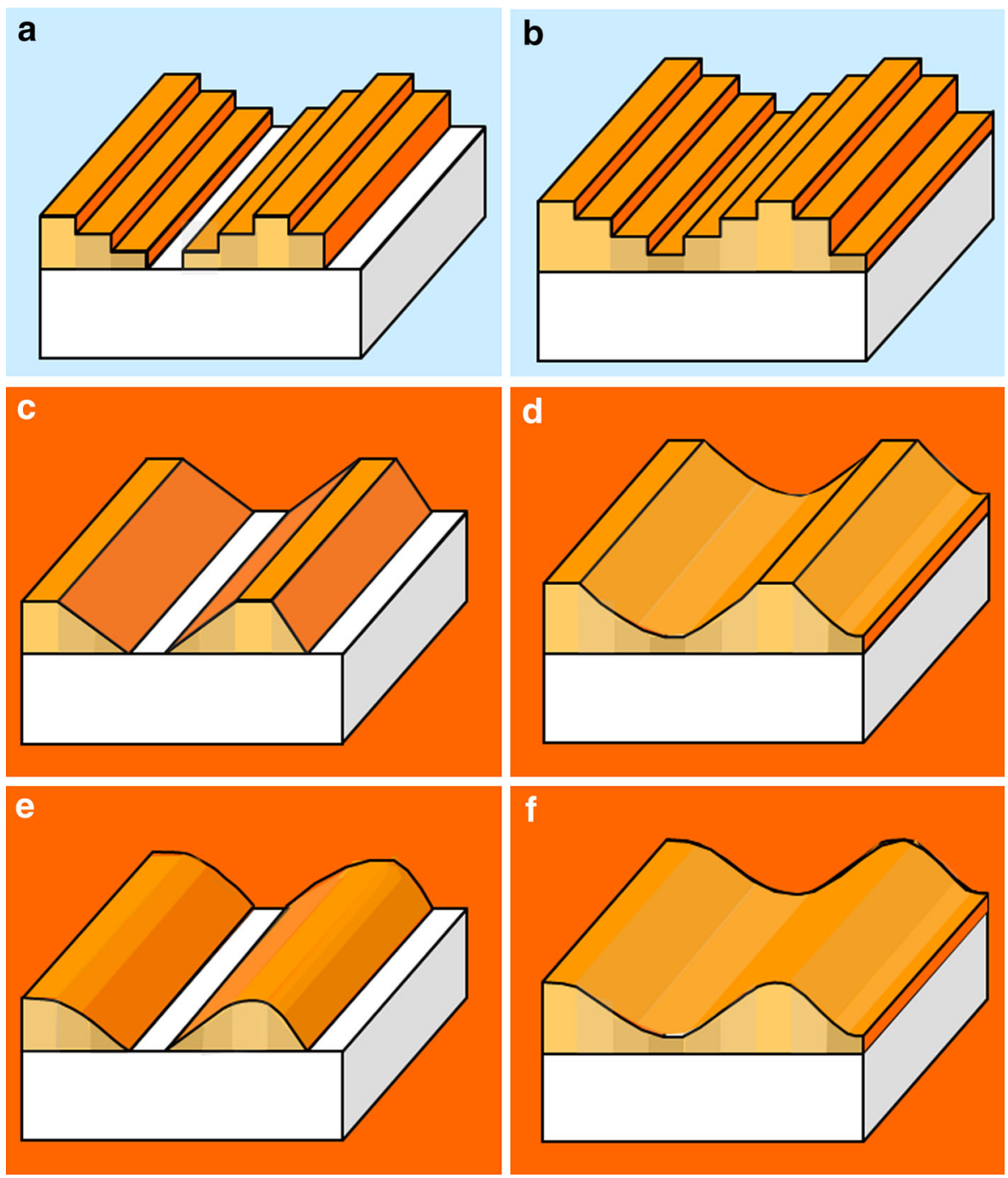

as few steps as possible to generate smooth surfaces with desired contours. In Fig. 7, stepped structures have been fabricated and reflowed into convex and concave lenses with spherical shapes. For comparison, both structures were transferred into silicon using DRIE and replication by thermal NIL.

\subsection{Replication}

Almost any 3D topography can be replicated by molding [67-89]. Since NIL is a replication process, in which a "copy" with negative polarity is created, the main challenge is that the viscous material is able to wet surfaces and penetrate into the cavities. This is normally enabled by channels (like in injection molding) or simply by the slitlike gap between the stamp and the substrate. While the precoated material is compressed between the protrusions, it is able to flow into the empty cavities into which the material is molded, until it conforms to the surface topographies and cannot flow further. Specific molding patterns can be achieved by porous membranes (e.g., for screen printing). Therefore, it is basically a process governed by wetting, viscous flow and capillary action of a material which is distributed, injected or redistributed.

Interestingly, two observations about the filling of cavity were found already at the beginning of research on NIL nanorheology, i.e., the abrupt filling of binary cavities by capillary action (so-called capillary bridges) and the continuous contact angle-based filling of 3D cavities with inclined sidewalls. In the first case, one was surprised to see that the mold filling can be essentially a binary process, with polymer "jumping" to the top (ceiling) of the cavity. This is caused by hydrodynamic instability, which is mostly dependent on the height of the cavity and the polymer viscosity. Then, either one or several mounds will form in the center of the cavity or, as seen in Fig. 9, capillary bridges form around stamp protrusions sinking into the thin polymer layer. In the second case, the contact 


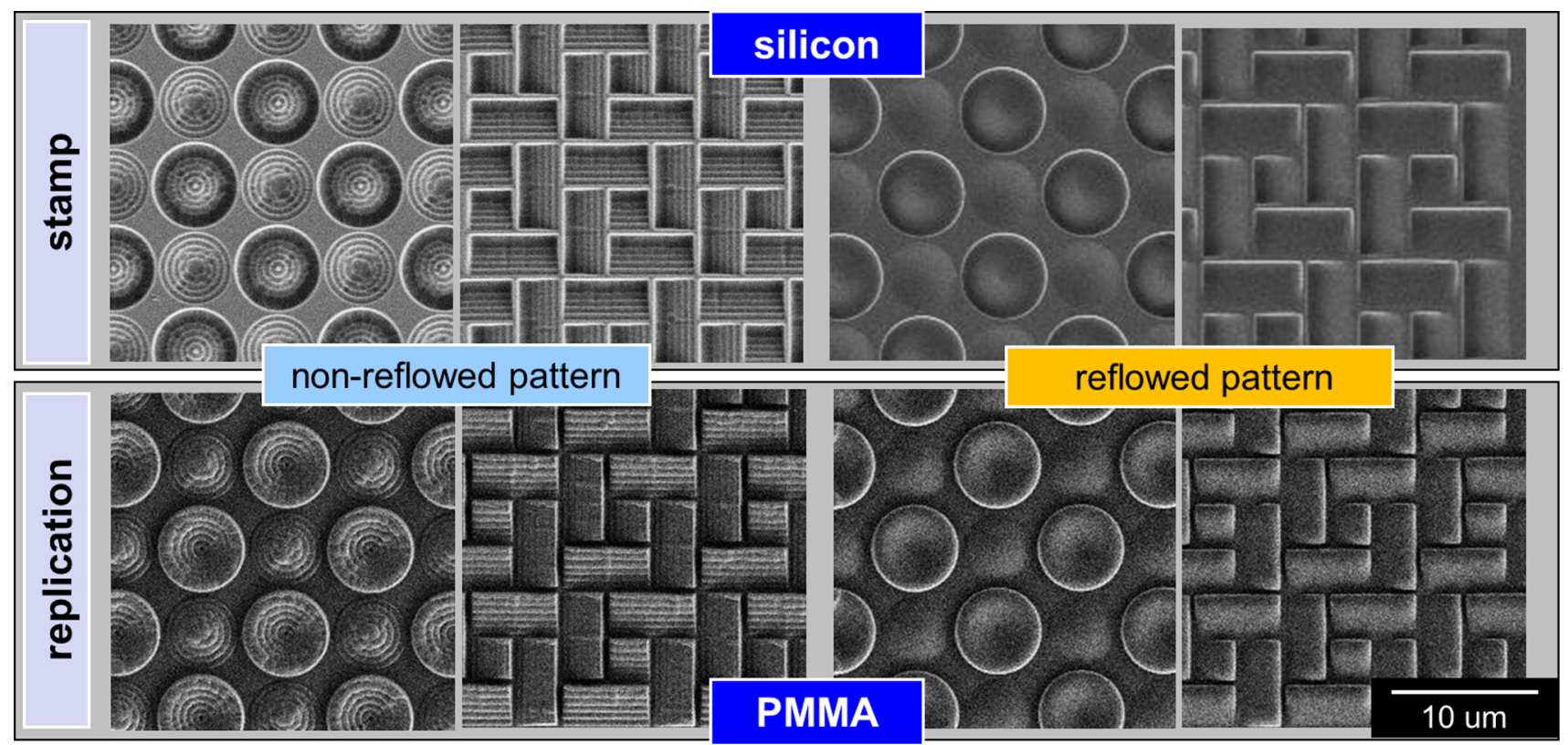

Fig. 7 SEM micrographs of silicon stamps (top) and replication in polymers (bottom) with 3D slopes and lens-like structures with concave and convex shapes. The stamps with stepped (top left) and

angle-based filling of structures, this behavior was clarified in more detail by using cavities with inclined sidewalls. This is the case if the polymer is able to form an equilibrium state and create the contact angle and thus the "energy optimized" surface. The polymer tries to contact the mold's sidewall with a specific angle and therefore moves into a cavity while trying to maintain this equilibrium. In case of typical NIL resists on antisticking layer (ASL)coated stamps with an angle of around $90^{\circ}\left(99^{\circ}\right.$ for the case here, mr-I T-85 from micro-resist technology $\mathrm{GmbH}$ ), for vertical sidewalls, this would be a flat surface, while for the inclined sidewalls a meniscus with a depression between neighboring sidewalls with opposed inclination. Both effects happen in a state where almost no squeeze flow is present. A possible finding is that $3 \mathrm{D}$ cavities are probably easier to fill than 2D cavities, which applies for smooth surfaces with no pinning and polymer contact angles.

The 3D quality is not only because of the surface topography, but also because the films can become so thin that it cannot be considered as homogeneous any more. In this case, an influence of the two interfaces of polymer-toambient and polymer-to-substrate has to be considered. However, the question whether there is a thickness-dependent $T_{\mathrm{g}}$, e.g., when using films much below $50 \mathrm{~nm}$ thickness, is still open. A further source of inhomogeneity could be the segregation of internal release agents toward the surface during spincoating or imprint. This is different from the concept of double resists with different molecular weights or even different properties. In the future, smooth (top right) surfaces were either fabricated from multilevel or from reflown resist (520 nm depth). Photographs adapted from [61]. Reproduced by permission. (C) 2015 Elsevier

functional materials will play a prominent role in application where the polymer film is not only considered as an intermediate layer for pattern transfer, but for new devices. Examples are resists made from block copolymers, with crystalline entities or filled with particles.

\subsection{Demolding}

In the best of cases, demolding is entirely a 2D process, which means that the stamp is lifted and detached from the structures in vertical direction [90-105]. For ideal structures with vertical sidewalls and no shrinkage, one would only have to distinguish between a state of adhesion on all surfaces, separation from horizontal planes, a state of sliding along vertical sidewalls and a state of complete separation, after a sudden detachment. Already slightly inclined sidewalls (with a so-called draft angle of a few degrees), like in Fig. 8, will change this sequence into a disruptive separation of these two surfaces without any sliding movement. The 3D quality is becoming important if deformation occurs before or during this separation, i.e., due to the sliding movement along vertical sidewalls. Extensive research has been performed on the shrinkage of the polymer structure which can be large enough that a pillar-like structure can shrink away and detach from the sidewalls before a vertical movement sets in. For thermal NIL, this can be during cooling, when different thermal expansion coefficients of polymer and silicon stamp become effective, and for UV-NIL this is due to crosslinking. 

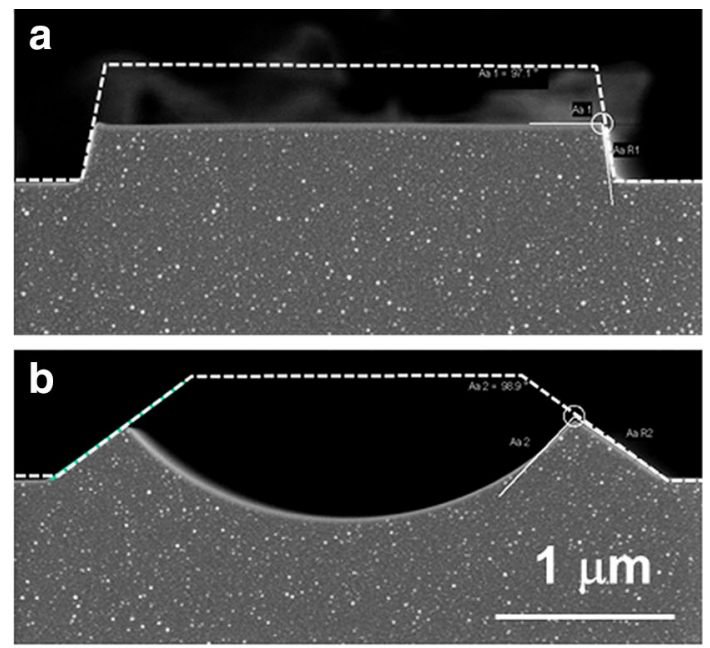

C

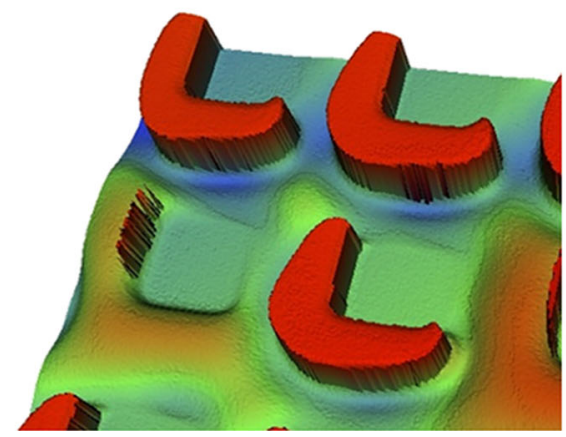

Fig. 8 SEM micrographs showing the 3D (incomplete) filling due to the formation of a contact angle-based meniscus with a nearly vertical and $\mathbf{b}$ sloped sidewalls, and $\mathbf{c}$ white light interferometry showing binary filling due to capillary bridges in a thermal NIL process. Photographs adapted from [77, 79]. Reproduced with permission. (c) 2015 a AVS and b IOP Publishing

Sidewall friction can be so high that thresholds to break or stretch fragile structures may be exceeded. Such processes are size dependent, since the material undergoes stress which needs to be balanced by cohesion within the molded material and adhesion to the substrate. Due to the shrinkage, structural details may also smoothen out, such as small pillars and sharp tips. Nevertheless, it is possible to mold sharp tips or ridges with $<10 \mathrm{~nm}$ radius (see Fig. 9).

As in replication, the quality of demolding is as a function of mechanical properties of the material and thus, in thermal NIL, of temperature. In addition to the softness and tendency to deform at temperatures slightly below $T_{\mathrm{g}}$, the polymer might glue better. In contrast to this, abrupt breaking is more probable at temperatures near ambient due to brittleness or extensive shrinkage. An example reduction in demolding force by using an optimized temperature is presented in Fig. 10. While elongation or rims may be tolerated for pattern transfer, breaking is not only creating defects but will contaminate the stamps. This is particularly severe if highly crosslinked silicon containing a

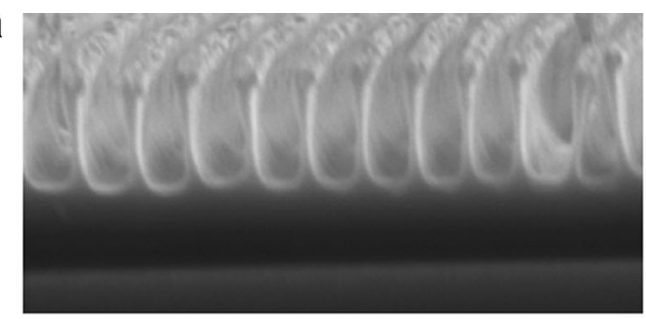

b

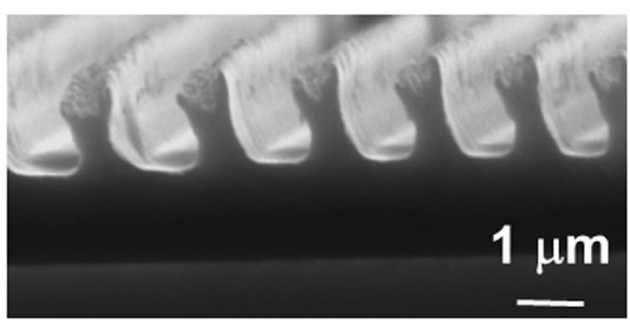

C $\mu \mathrm{m}$

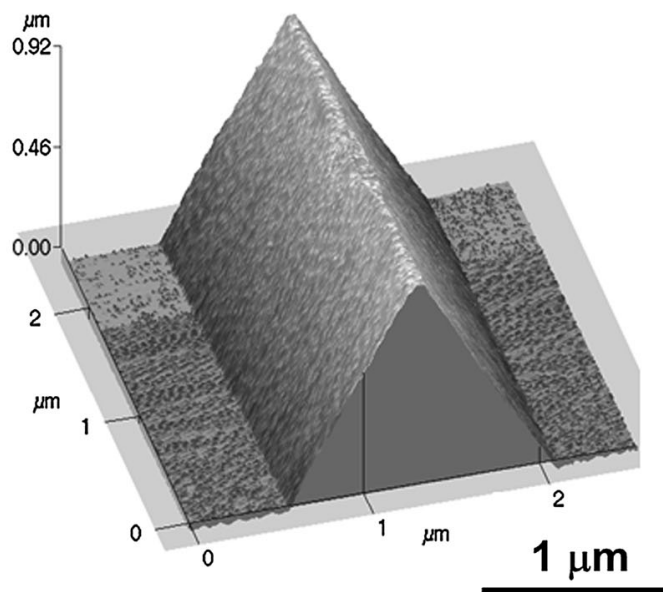

Fig. 9 SEM micrographs showing a elongated ridges in PMMA during demolding with $50 \%$ elongation, $\mathbf{b}$ rims from elongations near the sidewalls or $\mathbf{c}$ an molded PMMA structure from an anisotropically etched $\langle 100\rangle$ silicon wafer with a sub-20 nm top. Photographs adapted from [21, 40]. Reproduced by permission. (C) 2015 Elsevier

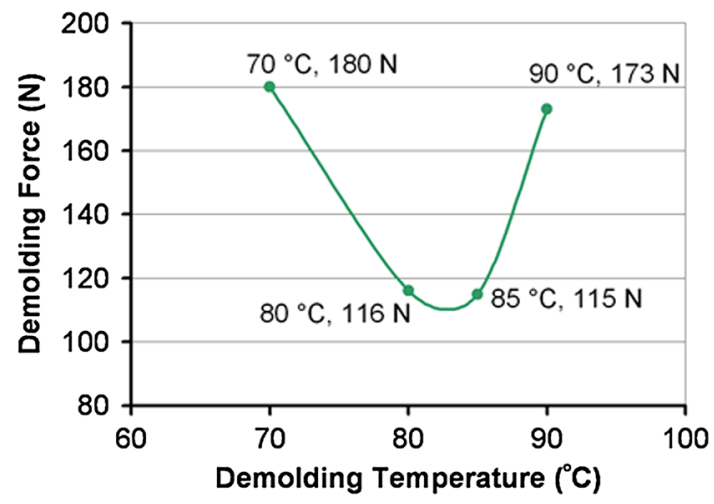

Fig. 10 Demolding force measured at different demolding temperatures in thermal NIL for a stamp with 500-nm-high pillars with vertical sidewalls. A more than $35 \%$ lower demolding force can be found at $82{ }^{\circ} \mathrm{C}$ in comparison with demolding at 70 and $90{ }^{\circ} \mathrm{C}$. Graph from [93]. Reproduced by permission. (C) 2015 Elsevier 
resist is used, which cannot be cleaned in $\mathrm{O}_{2}$-oxygen without damaging the stamp. Since in demolding, zero defectivity needs to be achieved, a reduction in the forces during demolding is vital for any kind of process optimization. This is not only achieved by surface smoothening, but also by geometrical optimization of the entire stamp (both locally and globally). In NIL, a defined draft angle would be highly desired as long as this would not result in structural variations of lateral sizes due to the residual layer etch.

\subsection{Pattern transfer and post-processing}

The typical pattern transfer process in NIL is the residual layer (window opening, breakthrough) etch, followed by the transfer into the substrate [106-122]. This can be done by anisotropic proportional etching, as long as a sufficient "resist height budget" is provided. In case of PMMA on $\mathrm{Si}$, as presented in Fig. 11, an etch ratio of almost 1:1 can be achieved, which is the prerequisite for structural preservation. Wet processes are, e.g., needed for lift-off processes, and for lateral removal of material. By using a lift-
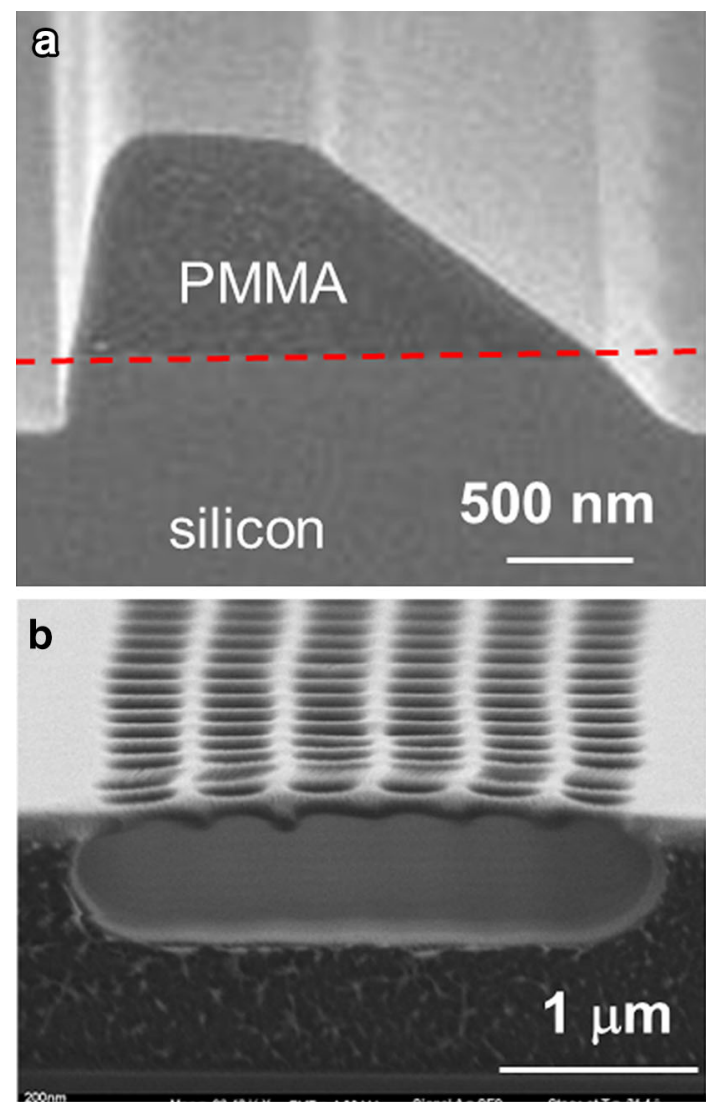

Fig. 11 SEM micrographs of a proportional anisotropic etching by RIE and $\mathbf{b}$ isotropic underetching of a lift-off resist in a solvent penetrating through the 200-nm resist pores. Photographs adapted from [7, 33]. Reproduced by permission. (C) 2015 Elsevier off resist (LOR), undercuts can be created below the patterned resist, either under single structures or below an array of structures. Thus, a channel can be created or a perforated membrane (Fig. 11).

Further post-processing can be achieved by functionalization, creation or modification of structures from an initial structure, assembly or thermal bonding, mix- and match with another technique. All of these processes have in common that the original structure is a means to make a second step possible. During the last year release of structures in membrane-like devices, additive and subtractive techniques such as etching, lift-off and electroplating were demonstrated and used for different applications [5, 33, 43, 44, 91, 114, 135].

\subsection{First conclusion: $2^{1 / 2} \mathrm{D}$ and $3 \mathrm{D}$ in the context of local and global aspects}

Is NIL therefore "more than 2D" or "less than true 3D"? In the context of this review, the transition from $2 \mathrm{D}$ to freeform 3D in Table 1 is understood as increasing complexity. The two intermediate definitions $\left(2 \frac{1}{2} \mathrm{D}\right.$ and $\left.3 \mathrm{D}\right)$ are used due to fundamental differences in complexity. Therefore, in my opinion, it is better to talk about $2 \mathrm{D}$ and $3 \mathrm{D}$ and keep in mind that real $2 \mathrm{D}$ is always more than $2 \mathrm{D}$ and true 3D is always less than freeform 3D. In Table 2, the $2 \mathrm{D}$ and $3 \mathrm{D}$ aspects are summarized, but with the distinction between "local" and "global." The global view of NIL will be on the substrate-topography relation, while local means single-cavity aspects. They are substantiated with examples which are considered as typically $2 \mathrm{D}$ and 3D. In the following, we will see that it is still not easy to keep this distinction between $2 \mathrm{D}$ and $3 \mathrm{D}$ valid. For example, while R2R, substrate conformal imprint lithography (SCIL), thermoforming and liquid transfer imprint lithography (LTIL) are locally 2D, they are globally 3D. In contrast to this, all 2D and 3D cavities on large planar substrates are globally 2D, as long as lateral shrinkage does not lead to shear over the entire substrate.

\section{NIL applications with 3D characteristics}

\subsection{Binary and multilevel applications}

Many of the NIL applications which were first published were essentially $2 \mathrm{D}$, i.e., applications which could have also been performed by other photon or electron-based lithography, but needed cost-effective solutions for which other current high-resolution lithography would not have been reasonable. The manufacturing of such devices, patterned magnetic media [123-126], wire grid polarizers [127-130] and high-brightness light emitting diodes (LED) 
Table 2 2D to 3D in NIL, with examples [5, 31, 62, 122]. Reproduced by permission. (C) 2015 AVS

\begin{tabular}{|c|c|c|c|c|}
\hline & \multicolumn{2}{|l|}{$2 \mathrm{D}$} & \multicolumn{2}{|l|}{$3 \mathrm{D}$} \\
\hline & Local & Global & Local & Global \\
\hline Origination & $\begin{array}{l}\text { Projection or scanning beam } \\
\text { lithography, moderate AR }\end{array}$ & $\begin{array}{l}\text { Wafer-like substrate and } \\
\text { stamp, surface topography }\end{array}$ & $\begin{array}{l}\text { Slopes, concave and convex } \\
\text { topography, high AR }\end{array}$ & $\begin{array}{l}\text { Bendable molds, } \\
\text { crowning, inflatable } \\
\text { molds, MESAs }\end{array}$ \\
\hline Replication & $\begin{array}{l}\text { Vertical stamp movement, complete } \\
\text { (binary) molding with enough } \\
\text { polymer "budget" }\end{array}$ & $\begin{array}{l}\text { Restricted lateral flow, } \\
\text { homogeneous residual } \\
\text { layer, roll embossing }\end{array}$ & $\begin{array}{l}\text { Non-vertical stamp } \\
\text { movement, contact angle- } \\
\text { based/incomplete filling, } \\
\text { meniscus }\end{array}$ & $\begin{array}{l}\text { Bent stamp for roll } \\
\text { embossing, printing on } \\
\text { topography } \\
\text { thermoforming, high } \\
\text { shrinkage }\end{array}$ \\
\hline Demolding & $\begin{array}{l}\text { Vertical movement with immediate } \\
\text { detachment from horizontal walls } \\
\text { and sliding at vertical sidewalls }\end{array}$ & $\begin{array}{l}\text { Separation movement } \\
\text { perpendicular to } \\
\text { structures, parallel plates, } \\
\text { large rolls }\end{array}$ & $\begin{array}{l}\text { Enlongation, ripping, defects, } \\
\text { collapse, shear }\end{array}$ & $\begin{array}{l}\text { High lateral shrinkage, } \\
\text { inhomogeneous } \\
\text { detachment/ } \\
\text { delamination due to } \\
\text { bending }\end{array}$ \\
\hline $\begin{array}{l}\text { Pattern } \\
\text { transfer }\end{array}$ & $\begin{array}{l}\text { Isotropic residual layer and substrate } \\
\text { etching, multilevel process with } \\
\text { proportional or successive etching }\end{array}$ & $\begin{array}{l}\text { Conformal casting, LTIL, } \\
\text { electroplating vertical } \\
\text { bonding, stacking }\end{array}$ & $\begin{array}{l}\text { Underetching, overgrowth, } \\
\text { surface smoothening, } \\
\text { conversion of steps into } \\
\text { slopes }\end{array}$ & $\begin{array}{l}\text { Thermoforming, bending, } \\
\text { flipping, deforming }\end{array}$ \\
\hline Example & $\begin{array}{l}\text { Anisotropically etched } \mathrm{Si} \text { with double } \\
\text { resist }\end{array}$ & $\begin{array}{l}\text { Bent hybrid stamp with } \\
\text { metal backbone }\end{array}$ & $\begin{array}{l}\text { Mixed 3D structures (NIL, } \\
\text { EBL and TASTE) }\end{array}$ & $\begin{array}{l}\text { Thermoformed foil with } \\
\text { nanopillars }\end{array}$ \\
\hline
\end{tabular}

[131-135] is essentially the patterning of binary structures. While this is basically also the case for high-end lithography in semiconductor microchip manufacturing, the NILbased dual damascene process used for creating electrical wires in the contact layer of a microprocessor has gained attention because it enables to reduce the total number of process steps for the 8 wiring levels (each of them consisting of two sub-levels), simply by using multilevel stamps with T-shaped structures. This would enable to pattern both sub-levels in one step [136] (Fig. 12), i.e., the lateral wires and vertical through-holes (vias), both aligned to each other. After electroplating both levels, the surface is planarized by chemical mechanical polishing (CMP) before the next connecting metal double layer is added. A similar concept was proposed by Hewlett-Packard for its self-aligned imprint lithography (SAIL) process [137] (Fig. 13). Also here, by adding one level (or more) to the stamp, a multilevel resist pattern is created which is thinned down one after the other. Thus, subsequent windows are opened to the substrate followed by a material-selective etching process. This can be used for the patterning of two metal layers on top of each other. It allows using one lithography step instead of one with precisely aligned levels ("encoded" in the stamp). This even enabled the large-area manufacturing of electronics on flexible substrates in a R2R process, where the ability of subsequent alignment is limited. However, although in both cases a multilevel approach was chosen, these processes are still $2 \mathrm{D}$ in principle, because they rely on proportional etching of the imprinted layer. Multiple etching steps into an imprinted resists with 3 levels enable to successively employ different pattern transfer processes. The stamp levels have to obey certain rules, i.e., the upper level has to be placed on the lower level, and no undercuts are allowed. This mask is essentially a double mask with different "height budgets" for pattern transfer.

Applications with "more than 2D" characteristics can be found in the areas of photonics and plasmonics, microand nanofluidics, tissue engineering, and biomimetics [138-143]. Special variants of NIL such as reverse NIL enable the fabrication of multilevel structures for negative index metamaterials and Fabry-Pérot filters, or biologically inspired omniphobic surfaces with undercuts. They are all applications where the concept of planar technology is still valid, or stacking of different layers, films and components is done [118-120]. 
a

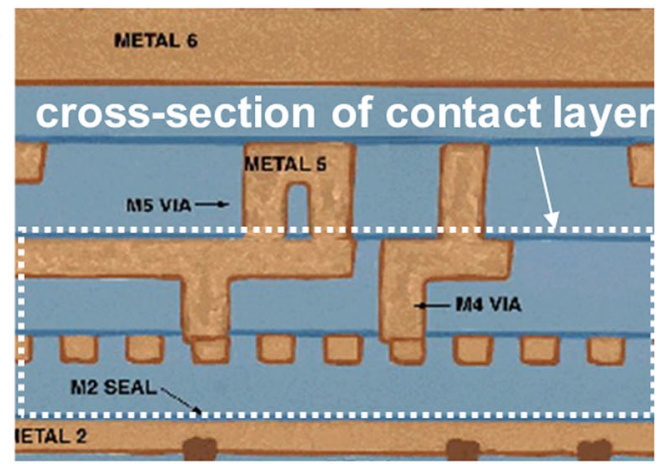

b
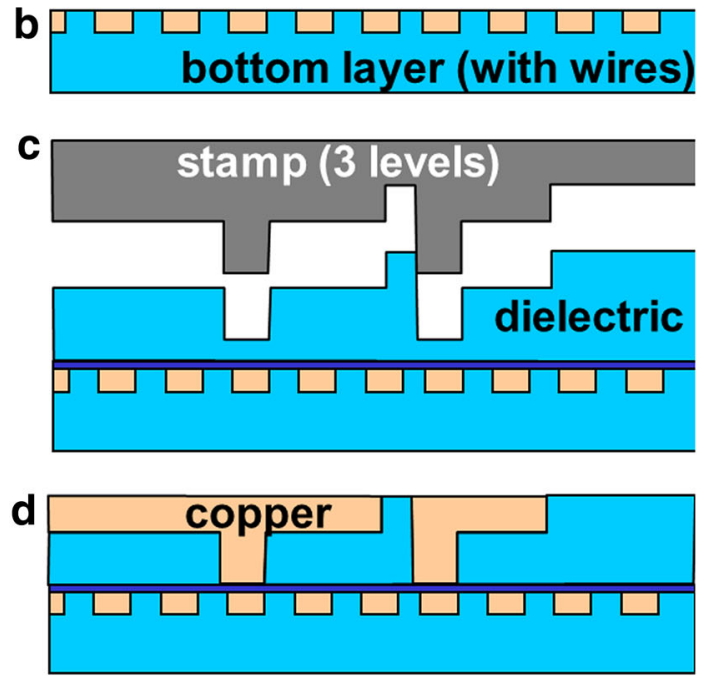

Fig. 12 a Schematics of a dual damascene process for the generation of a wiring layer in an IBM PX750 microprocessor, b Wires integrated in dielectric layer. c Imprint of transparent 3-level stamp into a dielectric precursor (UV-curable resist). d New copper layer after breakthrough-etch, electroplating, metal thinning by chemical mechanical polishing [136]. Reproduced by permission. (c) 2015 AVS

\subsection{Continuous topography applications}

In addition to the multilayer applications presented before, there are processes with global or local 3D structuring. As global 3D processes, printing on fibers and thermoforming of prepatterned films have been developed [26, 122]. Thermoforming is done from flat films which are locally stretched and bent until they conform to the outlines of a microcavity (see Table 2). If the film is patterned in advance, e.g., with a pillar structure, this film can be used to decorate both the bottom and the sidewalls of a microchannel. In [122], this was used to cover part of polymeric fuel cells with superhydrophobic surface patterns. Textile fibers with surface patterns along their axis can be done by extrusion, but for arbitrary surface patterns, e.g., perpendicular to the fiber, roll embossing has shown some a

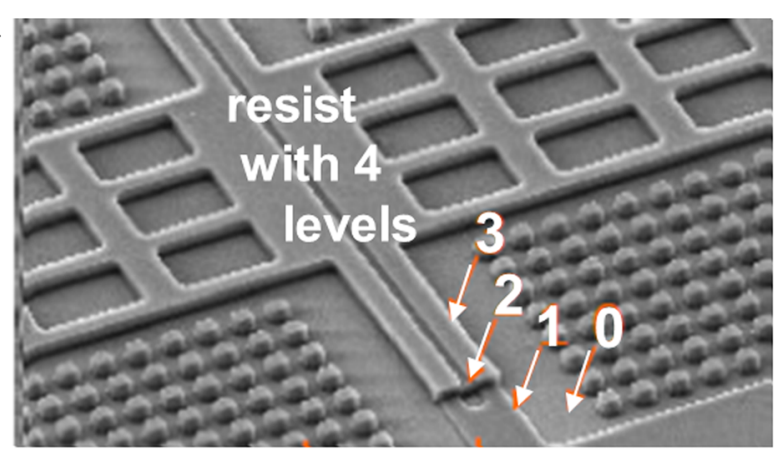

b

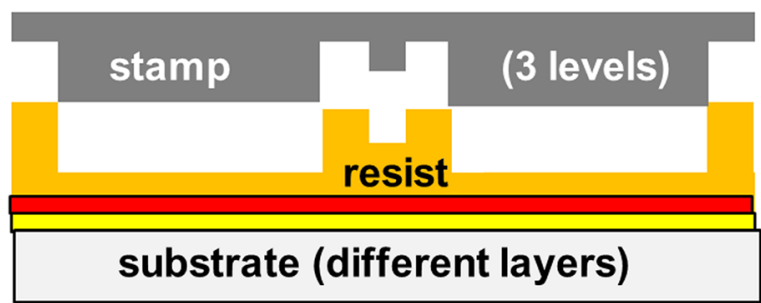

C

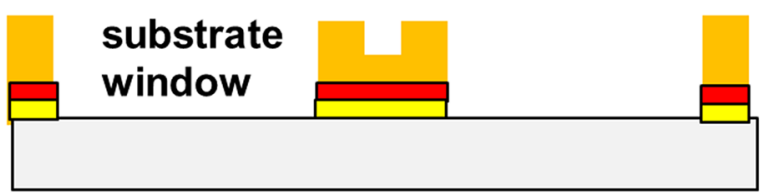

d

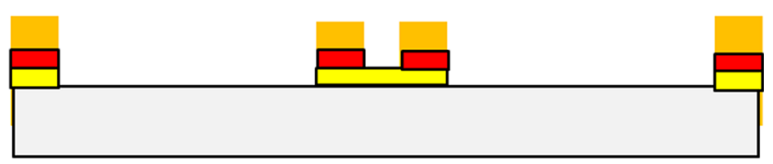

e

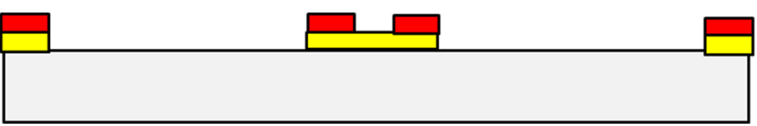

Fig. 13 a SEM micrograph of a patterned resist used for patterning transistors in flexible electronics. b-e Schematics of a self-aligned imprint lithography (SAIL) process by using multilayer stamps for selfaligned patterning. b Imprint of 3-level stamp by SAIL into a resist on multilayer metallization. $\mathbf{c}$ Residual layer etch of first level and etching of both metal layers. $\mathbf{d}$ Residual layer etch of second level and metal etching of upper metal layer [137]. Reproduced by permission. (C) 2015 Wiley

promising results. However, patterning of fibers with diameters of $180 \mu \mathrm{m}$ is not easy, because too high pressure can flatten a monolithic fiber when imprinting on its surface. The fiber is "multi-facetted" rather than entirely round. By using a core with a higher $T_{\mathrm{g}}$ material, the cladding can be imprinted. [26]. A hybrid three-dimensional nanofabrication method for producing vascular tissue engineering scaffold was employed by rolling up a patterned foil (so-called Swiss roll) [144]. In the following, an example for a local 3D process is presented (Fig. 14). Here, the TASTE process was used to generate a continuous funnel between micro- and nanochannels, which 
a

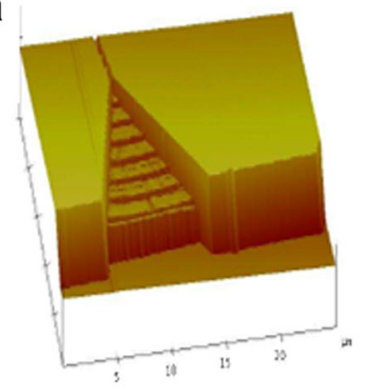

b
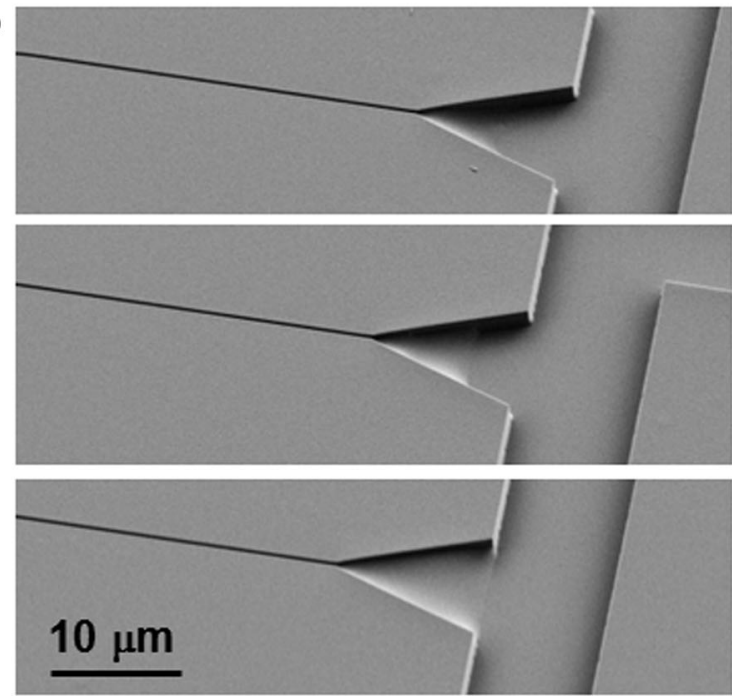

Fig. 14 Tapered inlet for nanofluidic applications in 1- $\mu$ m-thick resist, bridging the gap between a $10-\mu \mathrm{m}$-wide microchannel and a 30-nm-wide square nanochannel: a SFM micrograph with stepped and smoothed inlet, $\mathbf{b}$ three different tapers. Photographs adapted from [144, 145]. Reproduced with permission. Copyright (C) 2015 AVS

are needed to allow DNA molecules to penetrate into nanochannels without a mechanical threshold [145, 146]. For this, the process was optimized that reflow allowed to generate a slope both in vertical and lateral direction, bridging the gap between $1-\mu \mathrm{m}$-deep and $10-\mu \mathrm{m}$-wide microchannel to 30-nm-wide and 30-nm-deep nanochannel. This process can be further enhanced to fabricate defined wedges with tapers both in $x$ - and $y$-direction [147]. As it has been outlined in the beginning, even these processes have some $2 \mathrm{D}$ properties. Therefore, they are enabling to use replication techniques to fabricate copies from originals planar, either to be directly used, e.g., for stretching, bending and rolling, or to use them as an auxiliary mold for surface decoration of 3D molds, which are used for true 3D molding processes such as thermal injection molding [148, 149]. Before coming to the application of TASTE for the pixelized waveguide display illumination, a typical process chain is described in Fig. 15 from origination to replication using different process.

\section{Pixelized waveguide display illumination}

In the following, an example for a pixelized waveguide for illumination of displays is presented which includes different aspects of 3D: (a) The fabrication of 3D surface topographies by mix- and match of NIL and grayscale EBL, (b) the transformation of stepped into smooth structures using the TASTE process, (c) the replication of these structures by NIL with different replication processes with the ability to scale this up by using R2R NIL. This resulted in a demonstrator with a single LED for illumination. For this, single steps were developed to improve an existing process chain still based on binary structures. This $2 \mathrm{D}$ structuring has already met customers' requirements. Another demonstrator based on these 2D structures is presented in more detail in [28,31, 150-152]. Here, we put the process into the context of 3D patterning with different issues for modulated-dose EBL, fabrication of stamps with smooth slopes by thermal reflow and transfer into bendable stamps for R2R processes. Once scaled up to full screen size, these $3 \mathrm{D}$ structures inherently offer capabilities for higher brightness illumination.

\subsection{Monolithic back- or frontlight illumination devices}

For the illumination of displays, i.e., for liquid crystal (LCD)-based tablets and for electronic ink readers, different concepts have been developed [153-157]. The main difference between backlight illumination for transmissive and frontlight illumination for reflective pixel matrices. In both cases, light is coupled from discrete light sources into a screen-sized guide from one or several of its edges, which on its path illuminates the switching elements either from the back or from the front of the screen. Due to the need to reduce the thickness of the final device, these guides are nowadays realized as monolithic sheet waveguides, instead of composing them from sheets with different optical purposes. Light from edge-mounted white light LEDs enters the edge of the waveguide and is reflected internally until it exits through optical features imprinted onto the surface toward the display. This outcoupling can be done by binary diffraction gratings, by prism-like mirrors or a combination of both. The challenge is to distribute the light evenly over the entire area. For this, these elements have to be placed in a "gradient" along the light propagation, for which the density would need to be low near the pointsource like LEDs and high at the end of the waveguide. Additionally, they should lead to preferred light emission in the direction perpendicular to the waveguide. The density gradient can be achieved by variation of the sizes of these gratings or simply by increasing the number of small 

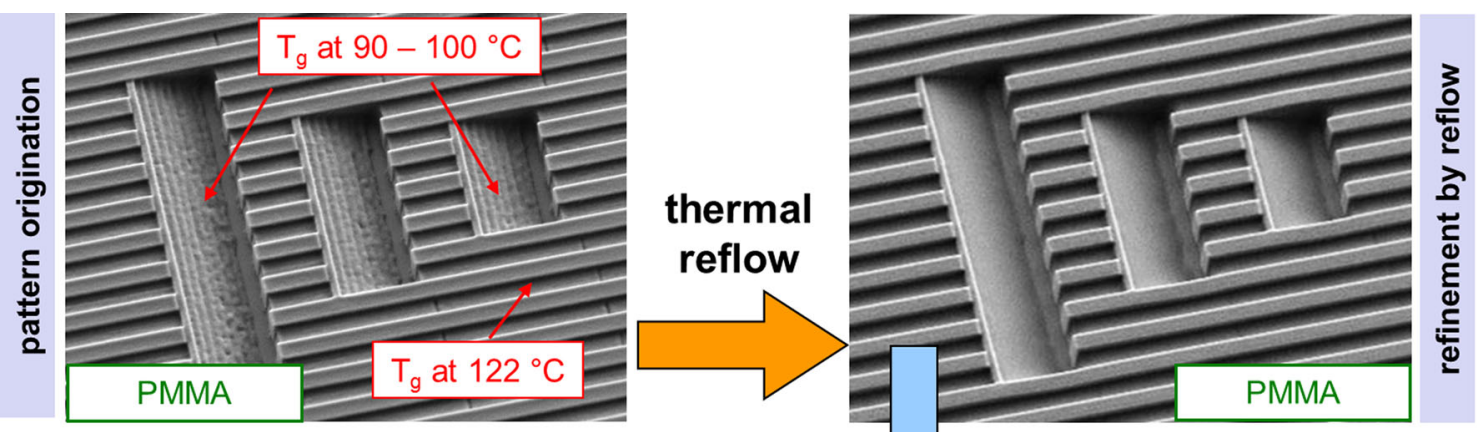

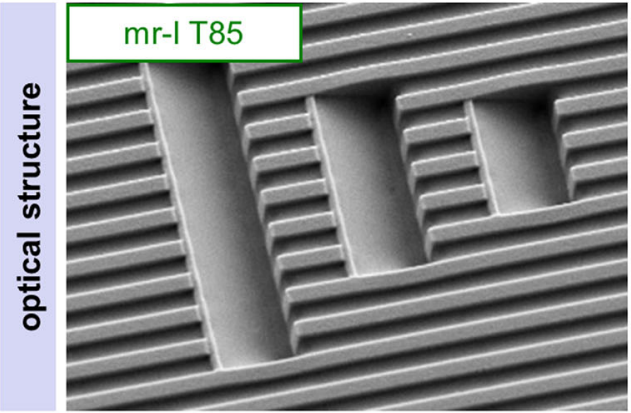

Fig. 15 Process chain comprising the key processes origination, replication and pattern transfer, here for $30^{\circ}$ slopes with $1 \mu \mathrm{m}$ height. The binary surface in the prepatterned resist line grating has $500 \mathrm{~nm}$ period and $250 \mathrm{~nm}$ depth. Imprint parameters for both PMMA and mr-I T85: $180{ }^{\circ} \mathrm{C}$ for $10 \mathrm{~min}$ at $15 \mathrm{MPa}$. Photographs adapted from [61]. Reproduced by permission. (C) 2015 AVS

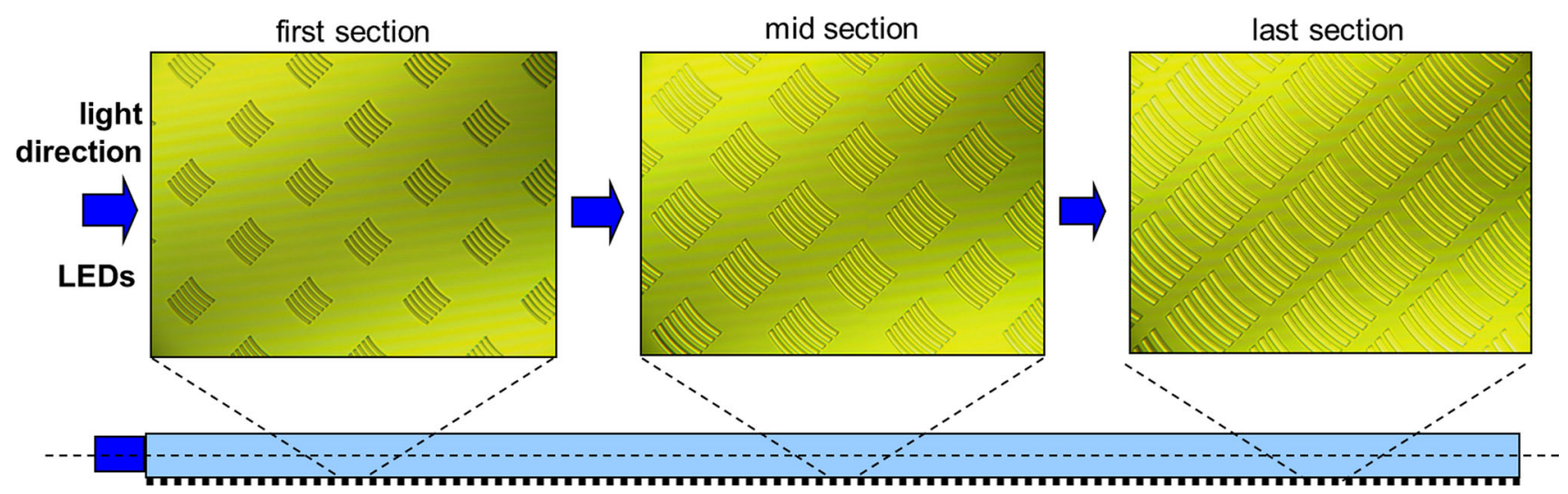

Fig. 16 Pixelized lightguide surface for backlighting devices: schematic and micrographs with outcoupling elements with varying size from the beginning to end of the lightguide

identical elements (pixels) in the same area. In Fig. 16, such a density gradient is illustrated by variation of the size of the outcoupling grating. Depending on the number and location of LEDs, the gratings have to be arranged over the entire waveguide by sophisticated computation which takes into account their placement in $x-y$, their orientation $\varphi$, and at the same time avoiding overlaps and stray light. Due to the multimode behavior of the waveguide and the color dispersion from the white light on its way, often additional surface gratings are needed to block modes which would result in unwanted color effects. In Fig. 17, an example of an outcoupling element with bent outline is presented, including linear surface gratings which were prepatterned in the resist by NIL.

\subsection{Fabrication process based on TASTE}

The stamp fabrication can be done as described in the origination section [7, 60-62]: Here the 3D process needs to be adapted to large area, considering varying density, requiring identical structuring for each angular orientation $\varphi$ in $x-y$, avoiding flats at the top (which is still characteristic of the reflow process due to the unexposed ridge), without visible stitching marks between EBL exposure 


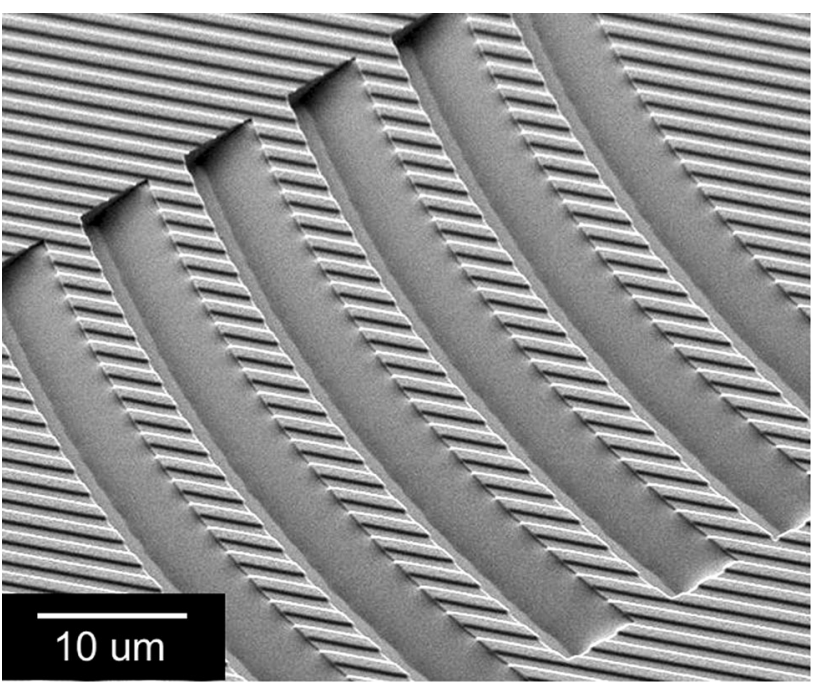

Fig. 17 SEM micrograph of an example of an outcoupling element on a pixelized lightguide surface for backlighting devices, including linear surface gratings which were prepatterned in the resist by NIL. Example from [60]

fields, but also in sub-field stitching (characteristic properties of Gaussian beam EBL). At the same time, writing time issues have to be respected, by keeping the number of dose steps as low as possible and dose differences between first and last step small enough that high exposure currents can be used without changing the aperture. For the current size and design, a process window was found which allowed writing a test design. The characteristic sizes are as follows: area $16 \times 16 \mathrm{~mm}^{2}$ for a single LED-based waveguide, EBL exposure field $320 \times 320 \mu \mathrm{m}^{2}, 4.5 \mu \mathrm{m}$ sub-field stitching and $20 \mathrm{~nm}$ step size. The simulation of optical texture was based on 74,000 grating units, and the optical design (i.e., orientation and density variation) was optimized for uniform illumination (collimation) in the active area, similar to [158, 159]. The slopes in the prepatterned $2-\mu \mathrm{m}$-thick resist were designed to exhibit a blazed angle $\alpha$ with approx. $45^{\circ}$. The outcoupling pixel elements were designed to have identical shape and sizes, but placed individually according to a precalculated map (see Fig. 18). Overlaps of single elements were avoided. Due to the large field size, the correction of the proximity effects which is characteristic for EBL, and particularly for 3D grayscale lithography, was of specific interest. Using a simulated point-spread function for exposing $2-\mu \mathrm{m}$-thick PMMA resist with $100 \mathrm{keV}$ electrons, the simulation was performed for $20 \times 20 \mu^{2}$ large areas using the GenISys Beamer software [49]. The density of the $20 \times 20 \mu \mathrm{m}^{2}$ pixel elements was varying from $100 \mu \mathrm{m}$ (distance from center to center) near the LED down to $40 \mu \mathrm{m}$ at the other end of the waveguide. At distances below $50 \mu \mathrm{m}$, the proximity effect has to be considered (see Fig. 18). This

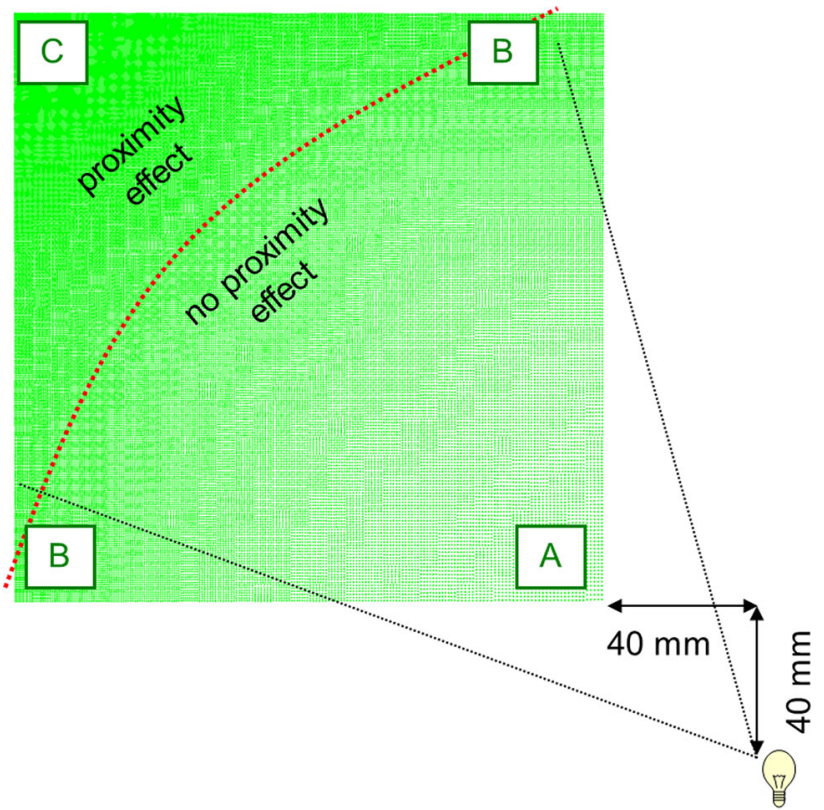

Fig. 18 Map of a $16 \times 16 \mathrm{~mm}^{2}$ active area with 74,000 outcoupling elements (pixel) and density variations with pixel to pixel distances in a $100 \mu \mathrm{m}, \mathbf{b} 55 \mu \mathrm{m}$ and $\mathbf{c} 40 \mu \mathrm{m}$. A single LED is placed at the lower right corner of the schematics

requires a dose compensation to avoid potential modification of geometry (e.g., inclination).

The replication for such structures is straightforward, similar to those already published in $[31,70,160,161]$. The first step is a replication into Ormostamp ${ }^{\circledR}$ by UV-NIL (see Fig. 15). These master copies, showing the outcoupling elements as protruding prisms, were then used for thermal imprint. Another process chain was the replication into polydimethylsiloxane (PDMS) which was then used for UV-NIL. In addition to the 3D structures, surface structures for mode breaking were integrated by imprint into the resist surface prior to grayscale lithography, using the process described in [62]. Figure 19 shows the qualitative outcome of such a replication, in this case a polymer film with a surface imprinted grating. The device was fabricated and tested. The white light was illuminating the screen with a homogeneity which proved to be satisfactory for the current application (details may not be disclosed), which was based on a non-optimized sawtooth structure and only basic compensation of the proximity effect. Therefore, significant further improvements can be expected once 3D structures are required.

\subsection{Further steps for upscaling}

For full screen manufacturing, i.e., of a full sized reader, this method would be dependent on high throughput 3D EBL, or laser-based alternatives with lower resolution. From the process described above, it becomes evident that 


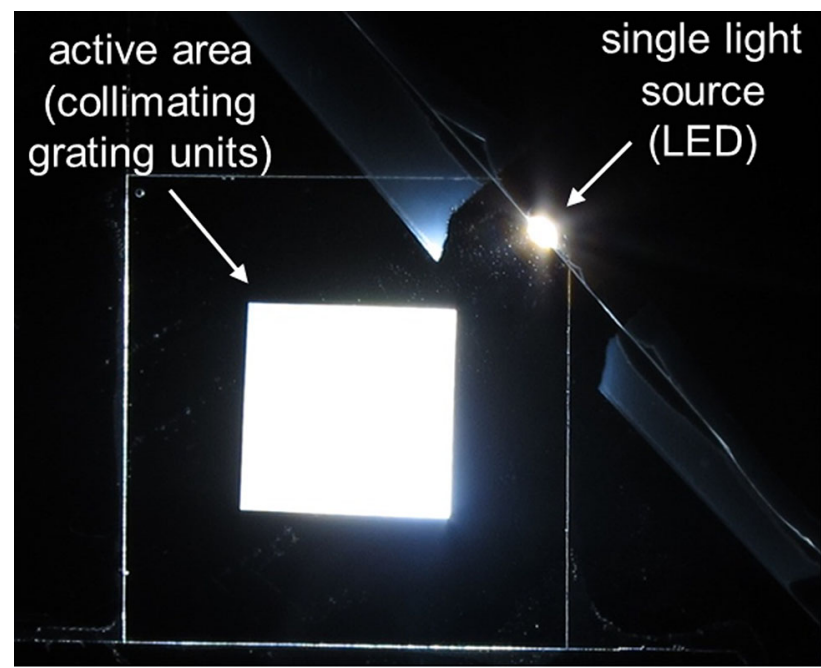

Fig. 19 Optical appearance of the LED-fed backlight test device with $16 \times 16 \mathrm{~mm}^{2}$ active area and 74,000 outcoupling elements

such as screen would contain several 100,000s of elements which would need both extensive computing of coordinates and exposure. For a larger screen, not only the number of elements needs to be dramatically enhanced, which leads to very sparse densities at one and extremely high density on the other side of the waveguide, but also the number of illuminating LEDs (Fig. 20). Such a device can only be written within reasonable times if different apertures are used enabling to use high doses in the sparse area and low doses in the dense areas of the lightguide. A design with different depths of outcoupling elements could also be envisaged, but would require different initial resist heights over the entire screen. Since the following processes are compatible with existing process chains (as described above or by fabrication of electroplated shims for R2R), it is expected that the origination will stay the most critical part of the process chain.

Apart from this approach, other routes can be employed to fabricate large-area lightguides for testing. Instead of manufacturing a full-area stamp by scanning laser or EB lithography, single stamplets can be created and replicated in a resist with step and stamp or step and repeat (S\&R) NIL. For this, a stamp with 3D blazed gratings with sharp teeth can be clamped into the head of the $S \& R$ machine with integrated angular rotation and printed into prepatterned PMMA substrate with defined lateral positions $x-$ $y$ and each angular orientation $\varphi$. Such sawtooth structures can be directly created by EBL and TASTE, but also from binary HAR structures with sawtooth designs in 2D. Such structures with lateral outlines of triangular shapes were manufactured using DRIE or LiGA, which-once released from the substrate and flipped by $90^{\circ}$-are transformed into a three-dimensional stamp with defined linear blazed teeth. Efforts have been undertaken resulting in electroplated nickel stamp with vertical sidewalls [162, 163]. The edge of the released nickel tool is used in the hot embossing of non-binary microstructures. DXRL is needed for achieving almost vertical sidewalls because due to the flipping, the vertical sidewalls will be translated into homogeneous height of each tooth. The thermal S\&R NIL process was performed with a SET 300 NIL stepper (a converted flip-chip bonder) with integrated rotation head, thus enabling to print linear gratings in different orientations with respect to the substrate outlines. Due to high number of required imprints in a large-area substrate, it is highly recommended to use different designs and stamplet sizes to cover the entire surface with varying density of outcoupling elements. Furthermore, wear and contamination of stamp has to be taken into account and backups have to be provided. This is possible by switching between multiple stamps by pick-and-place.

\section{Conclusion}

Is NIL 2D or 3D? As said before, this depends on several issues. In most cases, an exact replication of a surface with binary structures of moderate aspect ratio with high resolution is envisaged, ready to be transferred into the underlying substrate by RIE. Due to this "incremental" but significant improvement, 2D would remain to be the right description for such a process. Even aspect ratio enhancement by hard masks and successive transfer of stepped resist structures into the underlying substrate, make NIL continue to be a 2D process. Consequently, NIL exhibits enough 2D

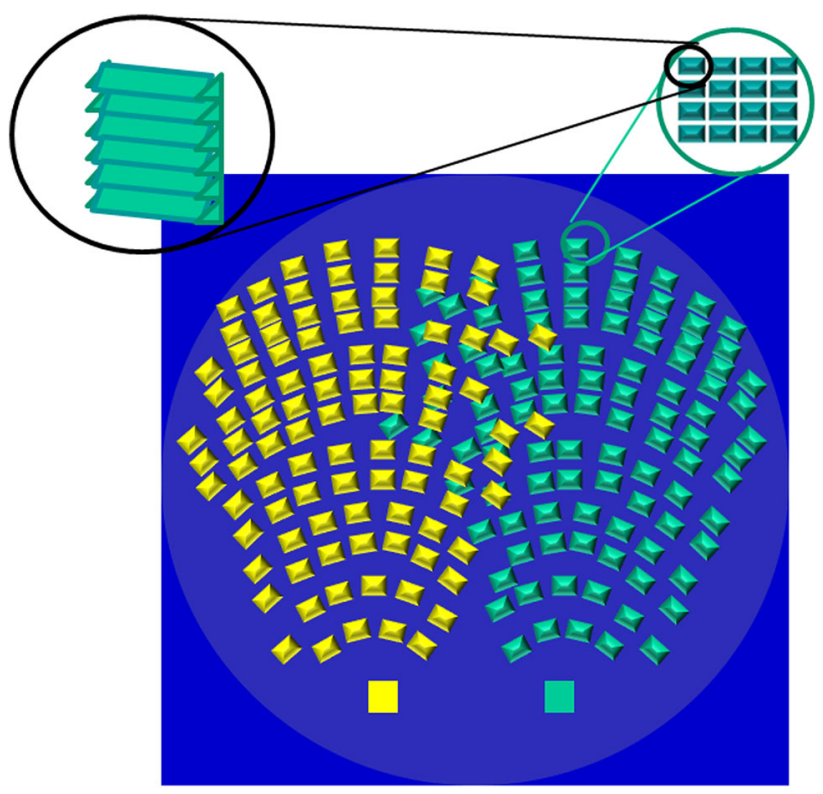

Fig. 20 Design with a possible, fan-like distribution of outcoupling element with two LEDs (squares at the bottom, in yellow and green), using an array of $4 \times 4$ pixels as a single stamplets (top) [146, 162] 
qualities that make it compatible with other high-end lithography and even step into fields which are too costly for them. But it is good to know about the "more than 2D" qualities of imprint: It enables to step out of the concept of planar technology with its specific boundary conditions, and even enable new concepts of semiconductor devices and processing which need $2 \frac{1}{2} \mathrm{D}$ and $3 \mathrm{D}[164,165]$. This can be considered as disruptive development within the framework of existing lithographic concepts, particularly, if functional materials are to be patterned. In the future, we could envisage applications where micro- and nanostructuring aspects are mixed in diverse ways. An example is given in this paper by presenting a backlight illumination waveguide. Consequently, NIL becomes truly 3D, but beyond this, it is also a time-dependent (dynamic) process (the 4th dimension) which enables "non-perfect" replication and demolding. One example is the use of partial filling [77, 79, 166], reflow and other processes which make use of selfordering or surface optimization. This can be done by immediate freezing or crosslinking of the viscous polymer before complete filling is achieved, or by use of a limited polymer volume which does not allow for complete filling. These "more than 3D" concepts will make NIL a technology which will not only make it a competitor to existing technologies, but also an integral part of any process development in future manufacturing of micro- and nanodevices.

Acknowledgments Taking part in the development of NIL over 20 years was a great opportunity. For a Swiss citizen, the view of the panorama of the Swiss Alps makes one believe that there is nothing else then 3D. Furthermore, there are many dishes, where viscous materials have either to be prepared and molded, even in 3D. This is melting of cheese for cheese fondue and raclette, casting of chocolate, baking of waffles [39]. The 20 years of NIL coincide with the development of NIL in the PSI-including LiGA and other "Gutenberg toolbox processes". Already before, I was involved in replication techniques, starting with the purchase of a hot embossing machine in the Institute of Microtechnology Mainz (IMM). Many thanks are due to all those researchers, engineers, technicians, and students, who contributed to the continuous development of the NIL technology in the Laboratory for Micro- and Nano-technology (LMN) at PSI, and especially J. Gobrecht, K. Vogelsang, S. Park, C. Spreu, M. Altana, S. Bellini and R. Kirchner. In particular, I want to thank A. Schleunitz, who developed TASTE from first proofs in 2009 into a reproducible 3D technique for backlight applications. This review was done within the framework of the INKA (Institute of Polymer Nanotechnology) of the University of Applied Sciences and Arts Nordwestschweiz (FHNW) and the PSI, which is a good example of collaboration between institutes with different foci but a joint interest in polymers research, applications and education.

\section{References}

1. R.C. Jaeger, C. Richard, Lithography. Introduction to Microelectronic Fabrication, 2nd edn. (Prentice Hall, Upper Saddle River, 2002), p. 315. ISBN 0-201-44494-1
2. M. Madou, Manufacturing Techniques for Microfabrication and Nanotechnology, 3rd edn. (CRC Press, Taylor \& Francis, Boca Rayton, FL). ISBN 978-1-4200-5519-1

3. E.W. Becker, W. Ehrfeld, P. Hagmann, A. Maner, D. Münchmeyer, Fabrication of microstructures with high aspect ratios and great structural heights by synchrotron radiation lithography, galvanoforming, and plastic moulding (LIGA process). Microelectron. Eng. 4(1), 35-56 (1986)

4. W. Menz, J. Mohr, O. Paul, Microsystem Technology, 2nd edn. (Wiley-VCH, Weinheim, 2008). ISBN: 978-3-527-61301-4

5. M. Messerschmidt, A. Schleunitz, C. Spreu, T. Werner, M. Vogler, F. Reuther, A. Bertz, H. Schift, G. Grützner, Thermal nanoimprint resist for the fabrication of high-aspect-ratio patterns. Microelectron. Eng. 98(8), 107-111 (2012)

6. S. Gorelick, V.A. Guzenko, J. Vila-Comamala, C. David, Direct e-beam writing of dense and high aspect ratio nanostructures in thick layers of PMMA for electroplating. Nanotechnology 21, 295303 (2010)

7. A. Schleunitz, H. Schift, Fabrication of 3-D patterns with vertical and sloped sidewalls by grayscale electron-beam lithography and thermal annealing. Microelectron. Eng. 88(8), 2736-2739 (2011)

8. J.K. Gansel, M. Latzel, A. Frölich, J. Kaschke, M. Thiel, M. Wegener, Tapered gold-helix metamaterials as improved circular polarizers. Appl. Phys. Lett. 100, 101109 (2012)

9. S. Fujimori, Fine pattern fabrication by the molded mask method (nanoimprint lithography) in the 1970s. Jpn. J. Appl. Phys. 48, 06FH01 (2009)

10. S.Y. Chou, P.R. Krauss, P.J. Renstrom, Imprint of sub- $25 \mathrm{~nm}$ vias and trenches in polymers. Appl. Phys. Lett. 67(21), 3114-3116 (1995)

11. J. Haisma, M. Verheijen, K. van den Heuvel, J. van den Berg, Mold-assisted lithography: a process for reliable pattern transfer. J. Vac. Sci. Technol. B 14, 4124-4128 (1996)

12. R.W. Jaszewski, H. Schift, J. Gobrecht, P. Smith, Hot embossing in polymers as a direct way to pattern resist. Microelectron. Eng. 41(42), 575-578 (1998)

13. M. Colburn, S. Johnson, M. Stewart, S. Damle, T. Bailey, B. Choi, M. Wedlake, T. Michaelson, S.V. Sreenivasan, J.G. Ekerdt, C.G. Willson, Step and flash imprint lithography: a new approach to high resolution patterning, in Proceedings of the SPIE 3676, (1999), pp. 379-385

14. B. Heidari, Nanoimprint lithography at the 6 in. wafer scale. J. Vac. Sci. Technol. B 18, 3557-3560 (2000)

15. W. Zhou, Nanoimprint Lithography: An enabling process for nanofabrication (Springer-Verlag Berlin Heidelberg, 2013), pp. 256. ISBN: 978-3-642-34427-5

16. M. Beck, M. Graczyk, I. Maximov, E.-L. Sarwe, T.G.I. Ling, M. Keil, L. Montelius, Improving stamps for $10 \mathrm{~nm}$ level wafer scale nanoimprint lithography. Microelectron. Eng. 61-62, 441-448 (2002)

17. Y. Hirai, Y. Tanaka, Application of nano-imprint lithography. J. Photopolym. Sci. Technol. 15, 475-480 (2002)

18. D.J. Resnick, S.V. Sreenivasan, C.G. Willson, Step \& flash imprint lithography. Mater. Today 8(2), 34-42 (2005)

19. L.J. Guo, Recent progress in nanoimprint technology and its applications. J. Phys. D Appl. Phys. 37, R123-R141 (2004)

20. L.J. Guo, Nanoimprint lithography: methods and material requirement. Adv. Mater. 19, 495-513 (2007)

21. L.J. Heyderman, H. Schift, C. David, J. Gobrecht, T. Schweizer, Flow behaviour of thin polymer films used for hot embossing lithography. Microelectron. Eng. 54, 229-245 (2000)

22. H.-C. Scheer, H. Schulz, A contribution to the flow behaviour of thin polymer films during hot embossing lithography. Microelectron. Eng. 56(3-4), 311-332 (2001)

23. H. Schift, L.J. Heyderman, Chapter (4), in Alternative Lithography-Unleashing the Potential of Nanotechnology. Book 
Series on Nanostructure Science and Technology, ed. by C. Sotomayor Torres, D.J. Lockwood (Kluwer Academic/Plenum Publishers, 2003), p. 46. ISBN 0-306-47858-7

24. H. Tan, A. Gilbertson, S.Y. Chou, Roller nanoimprint lithography. J. Vac. Sci. Technol. B 16, 3926-3928 (1998)

25. H. Schift, Roll embossing and roller imprint, Chapter in Science and new technology in nanoimprint, in Advanced Technology and Application of Nanoimprint, ed. by Y. Hirai. Frontier Publishing Co., Ltd., Japan, ISBN 4-902410-09-5, June 2006, pp. 74-89, and Japanese translation (extract) 90-93 (2006)

26. H. Schift, M. Halbeisen, U. Schütz, B. Delahoche, J. Gobrecht, Surface structuring of textile fibers using roll embossing. Microelectron. Eng. 83, 855-858 (2006)

27. S.H. Ahn, L.J. Guo, Large-area roll-to-roll and roll-to-plate nanoimprint lithography: a step toward high-throughput application of continuous nanoimprinting. ACS Nano 3(8), 2304-2310 (2009)

28. T. Mäkelä, T. Haatainen, J. Ahopelto, Roll-to-roll printed gratings in cellulose acetate web using novel nanoimprinting device. Microelectron. Eng. 88, 2045-2047 (2011)

29. N. Kooy, K. Mohamed, L.T. Pin, O.S. Guan, A review of roll-toroll nanoimprint lithography. Nanoscale Res. Lett. 9, 320 (2014)

30. H. Schift, Nanoimprint lithography: an old story in modern times? A review. J. Vac. Sci. Technol. B 26(2), 458-480 (2008)

31. A. Schleunitz, C. Spreu, T. Mäkelä, T. Haatainen, A. Klukowska, H. Schift, Hybrid working stamps for high speed rollto-roll nanoreplication with molded sol-gel relief on a metal backbone. Microelectron. Eng. 88(8), 2113-2116 (2011)

32. S. Merino, A. Retolaza, H. Schift, V. Trabadelo, Stamp deformation and its influence on residual layer homogeneity in thermal nanoimprint lithography. Microelectron. Eng. 85, 877-880 (2008)

33. H. Schift, S. Bellini, J. Gobrecht, Perforated polymer membranes fabricated by nanoimprint lithography. Microelectron. Eng. 83, 873-875 (2006)

34. H. Schift, A. Kristensen, Nanoimprint lithography_patterning resists using molding, in Chapter (Part A/9) in Handbook of Nanotechnology, 3rd edn. ed. by B. Bhushan, (Springer, Berlin, 2010), pp. 271-312. ISBN: 978-3-642-02524-2, XLVIII, with DVD

35. H. Schift, Nanoimprint lithography and micro-embossing in LiGA technology: similarities and differences. J. Microsyst. Technol. (2013). doi:10.1007/s00542-013-1915-8

36. H. Schift, P. Urwyler, P.M. Kristiansen, J. Gobrecht, Nanoimprint lithography process chains for the fabrication of micro- and nanodevices. J. Micro/Nanolithogr. MEMS MOEMS 13(3), 031303 (2014)

37. X. Cheng, Building 3D micro- and nano-structures through nanoimprint, Chapter 3, 59-85, in Three-Dimensional Nanoarchitectures: Designing Next-Generation Devices, ed. by W. Zhou, Z.L. Wang (Springer Science \& Business Media, New York, 2011), $556 \mathrm{p}$

38. M.T. Gale, Replication techniques for diffractive optical elements. Microelectron. Eng. 34, 321-339 (1997)

39. NaPa library of processes-nanopatterning and applications, ed. H. Schift, published by the NaPa-consortium, 3rd edn. (2014). (12 Dec 2014). http://www.psi.ch/lmn/helmut-schift

40. H. Schift, C. David, M. Gabriel, J. Gobrecht, L.J. Heyderman, W. Kaiser, S. Köppel, L. Scandella, Nanoreplication in polymers using hot embossing and injection molding. Microelectron. Eng. 53, 171-174 (2000)

41. Y. Xia, G.M. Whitesides, Soft lithography. Angew. Chem. Int. Ed. 37(5), 550-575 (1998)

42. B. Michel, A. Bernard, A. Bietsch, E. Delamarche, M. Geissler, D. Juncker, H. Kind, J.-P. Renault, H. Rothuizen, H. Schmid, P. Schmidt-Winkel, R. Stutz, H. Wolf, Printing meets lithography: soft approaches to high-resolution patterning. IBM J. Res. Dev. 45(5), 697-719 (2001)

43. L.J. Heyderman, H. Schift, C. David, B. Ketterer, M. Auf der Maur, J. Gobrecht, Nanofabrication using hot embossing lithography and electroforming. Microelectron. Eng. 57-58, 375-380 (2001)

44. L.J. Heyderman, B. Ketterer, D. Bächle, F. Glaus, B. Haas, H. Schift, K. Vogelsang, J. Gobrecht, L. Tiefenauer, O. Dubochet, P. Surbled, T. Hessler, High volume fabrication of customised nanopore membrane chips. Microelectronic Eng. 67-68, 208-213 (2003)

45. J.M. Stauffer, Y. Oppliger, P. Regnault, L. Baraldi, M.T. Gale, Electron beam writing of continuous resist profiles for optical applications. J. Vac. Soc. Technol. B 10, 2526-2529 (1992)

46. M.T. Gale, M. Rossi, H. Schuetz, Fabrication of continuousrelief micro-optical elements by direct laser writing in photoresist, laser-assisted fabrication of thin films and microstructures, in Proceedings of the SPIE 2045, (1994), pp. 54-62

47. E.A. Dobisz, S.L. Brandow, R. Bass, J. Mitterender, Effects of molecular properties on nanolithography in polymethyl methacrylate. J. Vac. Sci. Technol. B 18, 107-111 (2000)

48. G. Piaszenski, U. Barth, A. Rudzinski, A. Rampe, A. Fuchs, M. Bender, U. Plachetka, 3D structures for UV-NIL template fabrication with greyscale e-beam lithography. Microelectron. Eng. 84, 945-948 (2007)

49. GenISys beamer electron-beam lithography software, http:// genisys-gmbh.com/web/products/beamer.html

50. H.-B. Sun, S. Kawata, Two-photon photopolymerization and 3D lithographic microfabrication, in NMR - 3D Analysis - Photopolymerization. Advances in Polymer Science, vol 170 (Springer Berlin Heidelberg, 2004), pp. 169-273. ISBN: 978-3540-20510-4 (Print) 978-3-540-40000-4 (Online)

51. F. Holzner, P. Paul, M. Despont. L.L. Cheong, J. Hedrick, U. Dürig, A. Knoll, Thermal probe nanolithography: in situ inspection, high-speed, high-resolution, 3D, in Proceedings of the SPIE 8886, (2013), p. 888605

52. D. Pires, J.L. Hedrick, A. De Silva, J. Frommer, B. Gotsmann, H. Wolf, M. Despont, U. Duerig, A.W. Knoll, Nanoscale threedimensional patterning of molecular resists by scanning probes. Science 328, 732-735 (2010)

53. R. Garcia, A.W. Knoll, E. Riedo, Advanced scanning probe lithography. Nat. Nanotechnol. 9(8), 577-587 (2014)

54. C. David, Fabrication of stair-case profiles with high aspect ratios for blazed diffractive optical elements. Microelectron. Eng. 53, 677-680 (2000)

55. S. Landis, V. Reboud, T. Enot, C. Vizioz, Three dimensional on $300 \mathrm{~mm}$ wafer scale nano imprint lithography processes. Microelectron. Eng. 110, 198-203 (2013)

56. R. Huber, J. Conrad, L. Schmitt, K. Hecker, J. Scheurer, M. Weber, Fabrication of multilevel silicon structures by anisotropic deep silicon etching. Microelectron. Eng. 67-68, 410-416 (2003)

57. C.D. Popovic, R.A. Sprague, G.A. Neville, Connell, Techniques for monolithic fabrication of microlens arrays. Appl. Opt. 27, 1281-1284 (1988)

58. D. Daly, R.F. Stevens, M.C. Hutley, N. Davies, The manufacture of microlenses by melting photoresist. Meas. Sci. Technol. 1, 759-766 (1990)

59. H. Mekaru, Influence of residual layer on cross-sectional shape of thermal-reflowed photoresist structures. Microsyst. Technol. (2014). doi: 10.1007/s00542-014-2389-z

60. A. Schleunitz, H. Schift, Fabrication of 3-D nanoimprint stamps with continuous reliefs using dose-modulated electron beam lithography and thermal reflow. J. Micromech. Microeng. 20, 095002 (2010)

61. A. Schleunitz, V.A. Guzenko, M. Messerschmidt, H. Atasoy, R. Kirchner, H. Schift, Novel 3D micro- and nanofabrication 
method using thermally activated selective topography equilibration (TASTE) of polymers. Nano Converg. 1, 7 (2014)

62. A. Schleunitz, C. Spreu, M. Vogler, H. Atasoy, H. Schift, Combining nanoimprint lithography and a molecular weight selective thermal reflow for the generation of mixed 3-D structures. J. Vac. Sci. Technol. B 29(6), 06FC01 (2011)

63. R. Kirchner, H. Schift, Mobility based 3D simulation of selective, viscoelastic polymer reflow using surface evolver. J. Vac. Sci. Technol. B 32, 06F701 (2014)

64. R. Kirchner, A. Schleunitz, H. Schift, Energy-based thermal reflow simulation for $3 \mathrm{D}$ polymer shape prediction using the surface evolver. J. Micromech. Microeng. 24(5), 055010 (2014)

65. M. Tormen, A. Carpentiero, E. Ferrari, D. Cojoc, E. Di Fabrizio, Novel fabrication method for three-dimensional nanostructuring: an application to micro-optics. Nanotechnology 18, 385301 (2007)

66. H. Schift, C. Spreu, A. Schleunitz, J.J. Lee, Shape control of polymer reflow structures fabricated by nanoimprint lithography. Microelectron. Eng. 88, 87-92 (2011)

67. M.T. Gale, L.G. Baraldi, R.E. Kunz, Replicated microstructures for integrated optics, in Proceedings of the SPIE 2213, (1994), pp. $2-10$

68. L.G. Baraldi, Heissprägen in Polymeren für die Herstellung integriert-optischer Systemkomponenten, $\mathrm{PhD}$ thesis, Diss. ETH. Nr. 10762 (1994)

69. Y. Hirai, Y. Onishi, T. Tanabe, M. Shibata, T. Iwasaki, Y. Iriye, Pressure and resist thickness dependency of resist time evolutions profiles in nanoimprint lithography. Microelectron. Eng. $\mathbf{8 5}, 842-845$ (2008)

70. H.D. Rowland, A.C. Sun, P.R. Schunk, W.P. King, Impact of polymer film thickness and cavity size on polymer flow during embossing: toward process design rules for nanoimprint lithography. J. Micromech. Microeng. 15, 2414-2425 (2005)

71. T. Leveder, S. Landis, L. Davoust, N. Chaix, Flow property measurements for nanoimprint simulation. Microelectron. Eng. 84, 928-931 (2007)

72. T. Leveder, S. Landis, L. Davoust, N. Chaix, Optimization of demolding temperature for throughput improvement of nanoimprint lithography. Microelectron. Eng. 84, 953-957 (2007)

73. H. Teyssèdre, P. Gilormini, Extension of the natural element method to surface tension and wettability for the simulation of polymer flows at the micro and nano scales. J. Non-Newton. Fluid Mech. 200, 9-16 (2013)

74. N. Koo, U. Plachetka, M. Otto, J. Bolten, J.-H. Jeong, E.-S. Lee, H. Kurz, The fabrication of a flexible mold for high resolution soft ultraviolet nanoimprint lithography. Nanotechnology 19 , 225304 (2008)

75. N. Koo, M. Otto, J.W. Kim, J.-H. Jeong, H. Kurz, Press and release imprint: control of the flexible mold deformation and the local variation of residual layer thickness in soft UV-NIL. Microelectron. Eng. 88(6), 1033-1036 (2011)

76. H. Schift, S. Bellini, J. Gobrecht, F. Reuther, M. Kubenz, M.B. Mikkelsen, K. Vogelsang, Fast heating and cooling in nanoimprint using a spring-loaded adapter in a preheated press. Microelectron. Eng. 84, 932-936 (2007)

77. H. Schift, G. Kim, J.J. Lee, J. Gobrecht, 3D visualization of mold filling stages in thermal nanoimprint by white light interferometry and atomic force microscopy. Nanotechnology 20, 355301 (2009)

78. H. Schift, A. D’Amore, C. David, M. Gabriel, J. Gobrecht, W. Kaiser, D. Simoneta, Quantitative analysis of the molding of nanostructures. J. Vac. Sci. Technol. B 18(6), 3564-3568 (2000)

79. H. Schift, M. Altana, A. Schleunitz, Sidewall-angle dependent mold filling of three-dimensional microcavities in thermal nanoimprint lithography. J. Vac. Sci. Technol. B 30(6), 06FB09 (2012)
80. H. Schift, S. Park, J. Gobrecht, Nano-imprint-molding resists for lithography. J. Photopolym. Sci. Technol. (Jpn.) 16(3), 435-438 (2003)

81. V. Sirotkin, A. Svintsov, H. Schift, S. Zaitsev, Coarse-grain method for modeling of stamp and substrate deformation in nanoimprint. Microelectron. Eng. 84, 868-871 (2007)

82. M. Heckele, W.K. Schomburg, Review on micro molding of thermoplastic polymers. J. Micromech. Microeng. 14, R1 (2004)

83. M. Worgull, Hot Embossing, 1st edn. (William Andrew, Oxford, 2009)

84. S. Klammt, H. Müller, A. Neyer, Redirection of sunlight by microstructured components-simulation, fabrication and experimental results. Sol. Energy 86, 1660-1666 (2012)

85. H. Schift, L.J. Heyderman, M. Auf der Maur, J. Gobrecht, Pattern formation in hot embossing of thin polymer films. Nanotechnology 12, 173-177 (2001)

86. N. Chaix, C. Gourgon, S. Landis, C. Perret, M. Fink, F. Reuther, D. Mecerreyes, Influence of the molecular weight and imprint conditions on the formation of capillary bridges in nanoimprint lithography. Nanotechnology 17, 4082-4087 (2006)

87. H.-C. Scheer, A. Mayer, K. Dhima, S. Wang, C. Steinberg, Challenges with high aspect ratio nanoimprint. Microsyst. Technol. 20(10-11), 1891-1898 (2014)

88. Y. Hirai, UV-nanoimprint lithography (NIL) process simulation. Photopolym. Sci. Technol. (Jpn.) 23, 25-32 (2010)

89. H. Schulz, M. Wissen, H.-C. Scheer, Local mass transport and its effect on global pattern replication during hot embossing. Microelectron. Eng. 67-68, 657-663 (2003)

90. R.W. Jaszewski, H. Schift, B. Schnyder, A. Schneuwly, P. Gröning, The deposition on anti-adhesive ultra-thin teflon-like films and their interaction with polymers during hot embossing. Appl. Surf. Sci. 143, 301-308 (1999)

91. S. Park, H. Schift, C. Padeste, J. Gobrecht, Nanostructuring of anti-adhesive layer by hot embossing lithography. Microelectron. Eng. 61-62, 423-428 (2003)

92. H. Schift, S. Saxer, S. Park, C. Padeste, U. Pieles, J. Gobrecht, Controlled co-evaporation of silanes for nanoimprint stamps. Nanotechnology 16, S171-S175 (2005)

93. V. Trabadelo, H. Schift, S. Merino, S. Bellini, J. Gobrecht, Measurement of demolding forces in full wafer thermal nanoimprint. Microelectron. Eng. 85, 907-909 (2008)

94. S. Merino, H. Schift, A. Retolaza, T. Haatainen, The use of automatic demolding in nanoimprint lithography processes. Microelectron. Eng. 84, 958-962 (2007). doi:10.1016/j.mee.2007.01.023

95. Y. Guo, G. Liu, Y. Xiong, Y. Tian, Study of the demolding process-implications for thermal stress, adhesion and friction control. J. Micromech. Microeng. 17, 9-19 (2007)

96. H. Takagi, M. Takahashi, R. Maeda, Y. Onishi, Y. Iriye, T. Iwasaki, Y. Hirai, Experimental and numerical analyses on recovery of polymer deformation after demolding in the hot embossing process. J. Vac. Sci. Technol. B 26, 2399-2404 (2008)

97. S. Park, Z. Song, L. Brumfield, A. Amirsadeghi, J. Lee, Demolding temperature in thermal nanoimprint lithography. Appl. Phys. A 97(2), 395-402 (2009)

98. H. Kawata, K. Kubo, Y. Watanabe, J. Sakamoto, M. Yasuda, Y. Hirai, Effects of mold side wall profile on demolding characteristics. Jpn. J. Appl. Phys. 49(6S), 06GL15 (2010)

99. M.E. Dirckx, D.E. Hardt, Analysis and characterization of demolding of hot embossed polymer microstructures. J. Micromech. Microeng. 21, 085024 (2011)

100. K. Kuwabara, A. Miyauchi, High-aspect-ratio nanopillar structures fabricated by nanoimprinting with elongation phenomenon. J. Vac. Sci. Technol. B 26, 582-584 (2008)

101. S. Möllenbeck, N. Bogdanski, M. Wissen, H.-C. Scheer, J. Zajadacz, K. Zimmer, Investigation of the separation of 3D-structures with undercuts. Microelectron. Eng. 84, 1007-1010 (2007) 
102. S. Möllenbeck, N. Bogdanski, A. Mayer, H.-C. Scheer, J. Zajadacz, K. Zimmer, Moulding of arrowhead structures. Microelectron. Eng. 86, 608-610 (2009)

103. G. Shao, J. Wu, Z. Cai, W. Wang, Fabrication of elastomeric high-aspect-ratio microstructures using polydimethylsiloxane (PDMS) double casting technique. Sens. Actuators A 178, 230-236 (2012)

104. P.K. Sahoo, K. Vogelsang, H. Schift, H.H. Solak, Surface plasmon resonance in near field coupled gold cylinder array fabricated by EUV-interference lithography and hot embossing. Appl. Surf. Sci. 256(2), 431-434 (2009)

105. A. Finn, B. Lu, R. Kirchner, X. Thrun, K. Richter, W.-J. Fischer, High aspect ratio pattern collapse of polymeric UV-nano-imprint molds due to cleaning. Microelectron. Eng. 110, 112-118 (2013)

106. M. Miller, G. Doyle, N. Stacey, F. Xu, S.V. Sreenivasan, M. Watts, D.L. LaBrake, Fabrication of nanometer sized features on non-flat substrates using a nano-imprint lithography process, in Proceedings of the SPIE 5751, (2005), pp. 994-1002

107. D.J. Resnick, G. Schmid, M. Miller, G. Doyle, C. Jones, D. LaBrake, Step and flash imprint lithography template fabrication for emerging market applications, in Proceedings of the SPIE, vol. 6607 (2007), p. 66070T

108. T. Ogawa, S. Takei, B.M. Jacobsson, R. Deschner, W. Bell, M.W. Lin, Y. Hagiwara, M. Hanabata, C.G. Willson, Planarizing material for reverse-tone step and flash imprint lithography, in Proceedings of the SPIE 7637, (2010), p. 763708

109. N. Chaix, C. Gourgon, C. Perret, S. Landis, T. Leveder, Nanoimprint lithography processes on $200 \mathrm{~mm} \mathrm{Si} \mathrm{wafer} \mathrm{for}$ optical application: residual thickness etching anisotropy. J. Vac. Sci. Technol. B 25, 2346-2351(2007)

110. C.W. Jurgensen, E.S.G. Shaqfeh, Factors controlling the etching rate and etching profile in the $\mathrm{O}_{2}$ reactive ion etching pattern transfer step in multilevel lithography. Polym. Eng. Sci. 29(13), 878-881 (1989)

111. Y. Tsuji, M. Yanagisawa, H. Yoshinaga, K. Hiratsuka, Study of reactive ion etching for reverse tone nanoimprint process. J. Phys. Conf. Ser. 191, 012010 (2009)

112. D.L. Olynick, J. Alexander Liddle, B.D. Harteneck, S. Cabrini, I.W. Rangelow, Nanoscale pattern transfer for templates, NEMs, and nano-optics, in Proceedings of the SPIE 6462, vol. 64620J (2007)

113. S.Y. Chou, P.R. Krauss, Imprint lithography with sub-10 nm feature size and high throughput. Microelectron. Eng. 35, 237-240 (1997)

114. H. Schift, R.W. Jaszewski, C. David, J. Gobrecht, Nanostructuring of polymers and fabrication of interdigitated electrodes by hot embossing lithography. Microelectron. Eng. 46, 121-124 (1999)

115. D. Makarov, L. Baraban, I.L. Guhr, J. Boneberg, H. Schift, J. Gobrecht, G. Schatz, P. Leiderer, M. Albrecht, Arrays of magnetic nanoindentations with perpendicular anisotropy. Appl. Phys. Lett. 90(9), 093117 (2007)

116. P. Carlberg, M. Graczyk, E.-L. Sarwe, I. Maximov, M. Beck, L. Montelius, Lift-off process for nanoimprint lithography. Microelectron. Eng. 67-68, 203-207 (2003)

117. C.-L. Wu, C.-K. Sung, P.-H. Yao, C.-H. Chen, Sub- 15 nm linewidth gratings using roll-to-roll nanoimprinting and plasma trimming to fabricate flexible wire-grid polarizers with low colour shift. Nanotechnology 24, 265301 (2013)

118. T. Borzenko, M. Tormen, G. Schmidt, L.W. Molenkamp, H. Janssen, A polymer bonding process for nanolithography. Appl. Phys. Lett. 79(14), 2246-2248 (2001)

119. X.D. Huang, L.-R. Bao, X. Cheng, L.J. Guo, S.W. Pang, A.F. Yee, Reversal imprinting by transferring polymer from mold to substrate. J. Vac. Sci. Technol. B 20, 2872-2876 (2002)
120. N. Kehagias, V. Reboud, G. Chansin, M. Zelsmann, C. Jeppesen, C. Schuster, M. Kubenz, F. Reuther, G. Gruetzner, C.M. Sotomayor Torres, Reverse-contact UV nanoimprint lithography for multilayered structure fabrication. Nanotechnology 18, 175303 (2007)

121. C. Moormann, N. Koo, J. Kim, U. Plachetka, F. Schlachter, C. Nowak, Liquid transfer nanoimprint replication on non-flat surfaces for optical applications. Microelectron. Eng. 100, 28-32 (2012)

122. T. Senn, Ch. Waberski, J. Wolf, J.P. Esquivel, N. Sabaté, B. Löchel, 3D structuring of polymer parts using thermoforming processes. Microelectron. Eng. 88, 11-16 (2011)

123. S.Y. Chou, M.S. Wei, P.R. Krauss, P.B. Fischer, Single-domain magnetic pillar array of $35 \mathrm{~nm}$ diameter and 65 Gbits/in. 2 density for ultrahigh density quantum magnetic storage. J. Appl. Phys. 76(10), 6673-6675 (1994)

124. J. Lille, K. Patel, R. Ruiz, T.-W. Wu, H. Gao, L. Wan, G. Zeltzer, E. Dobisz, T.R. Albrecht, Imprint lithography template technology for bit patterned media (BPM), in Proceedings of the SPIE 8166, Photomask Technology, (2011), p. 816626

125. L. Wan, R. Ruiz, H. Gao, K.C. Patel, J. Lille, G. Zeltzer, E.A. Dobisz, A. Bogdanov, P.F. Nealey, T.R. Albrecht, Fabrication of templates with rectangular bits on circular tracks by combining block copolymer directed self-assembly and nanoimprint lithography. J. Micro/Nanolithogr. MEMS MOEMS 11(3), 031405 (2012)

126. R.A. Griffiths, A. Williams, C. Oakland, J. Roberts, A. Vijayaraghavan, T. Thomson, Directed self-assembly of block copolymers for use in bit patterned media fabrication. J. Phys. D Appl. Phys. 46, 503001 (2013)

127. S.-W. Ahn, K.-D. Lee, J.-S. Kim, S.H. Kim, J.-D. Park, S.-H. Lee, P.-W. Yoon, Fabrication of a $50 \mathrm{~nm}$ half-pitch wire grid polarizer using nanoimprint lithography. Nanotechnology 16, 1874-1877 (2005)

128. F. Meng, G. Luo, I. Maximov, L. Montelius, J. Chu, H. Xu, Fabrication and characterization of bilayer metal wire-grid polarizer using nanoimprint lithography on flexible plastic substrate. Microelectron. Eng. 88, 3108-3112 (2011)

129. N.C. Lindquist, P. Nagpa, K.M. McPeak, D.J. Norris, S.-H. Oh, Engineering metallic nanostructures for plasmonics and nanophotonics. Rep. Prog. Phys. 75, 036501 (2012)

130. L. Wang, H. Schift, J. Gobrecht, Y. Ekinci, P.M. Kristiansen, H.H. Solak, K. Jefimovs, High-throughput fabrication of compact and flexible bilayer nanowire grid polarizers for deep-ultraviolet to infrared range. J. Vac. Sci. Technol. B 32, 031206 (2014)

131. R. Ji, M. Hornung, M.A. Verschuuren, R. van de Laar, J. van Eekelen, U. Plachetka, M. Moeller, C. Moormann, UV enhanced substrate conformal imprint lithography (UV-SCIL) technique for photonic crystals patterning in LED manufacturing. Microelectron. Eng. 87(5-8), 963-967 (2010)

132. M.A. Verschuuren, P. Gerlach, H.A. van Sprang, A. Polman, Improved performance of polarization-stable VCSELs by monolithic sub-wavelength gratings produced by soft nano-imprint lithography. Nanotechnology 22, 505201 (2011)

133. Y.-C. Lee, S.-C. Yeh, Y.-Y. Chou, P.-J. Tsai, J.-W. Pan, H.-M. Chou, C.-H. Hou, Y.-Y. Chang, M.-S. Chu, C.-H. Wu, C.-H. Ho, High-efficiency InGaN-based LEDs grown on patterned sapphire substrates using nanoimprinting technology. Microelectron. Eng. 105, 86-90 (2013)

134. L. Cui, J.-C. Han, G.-G. Wang, H.-Y. Zhang, R. Sun, L.-H. Li, Large-scale fabrication of nanopatterned sapphire substrates by annealing of patterned Al thin films by soft UV-nanoimprint lithography. Nanoscale Res. Lett. 8, 472-477 (2013)

135. H. Schift, S. Park, C.-G. Choi, C.-S. Kee, S.-P. Han, K.-B. Yoon, J. Gobrecht, Fabrication process for polymer photonic crystals using nanoimprint lithography. Nanotechnology 16, S261-S265 (2005) 
136. M.D. Stewart, J.T. Wetzel, G.M. Schmid, F. Palmieri, E. Thompson, E.K. Kim, D. Wang, K. Sotodeh, K. Jen, S.C. Johnson, J. Hao, M.D. Dickey, Y. Nishimura, R.M. Laine, D.J. Resnick, C.G. Willson, Direct imprinting of dielectric materials for dual damascene processing, in Proceedings of the SPIE 5751, (2005), pp. 210-218

137. H.-J. Kim, M. Almanza-Workman, B. Garcia, O. Kwon, F. Jeffrey, S. Braymen, J. Hauschildt, K. Junge, D. Larson, D. Stieler, A. Chaiken, B. Cobene, R. Elder, W. Jackson, M. Jam, A. Jeans, H. Luo, P. Mei, C. Perlov, C. Taussig, Roll-to-roll manufacturing of electronics on flexible substrates using selfaligned imprint lithography (SAIL). J. Soc. Inf. Disp. 17(11), 963-970 (2009)

138. J.M. Fedeli, L. Di Cioccio, D. Marris-Morini, L. Vivien, R. Orobtchouk, P. Rojo-Romeo, C. Seassal, F. Mandorlo, Development of silicon photonics devices using microelectronic tools for the integration on top of a CMOS wafer. Adv. Opt. Technol. 2008, 412518 (2008)

139. I. Bergmair, B. Dastmalchi, M. Bergmair, A. Saeed, W. Hilber, G. Hesser, C. Helgert, E. Pshenay-Severin, T. Pertsch, E.B. Kley, U. Hübner, N.H. Shen, R. Penciu, M. Kafesaki, C.M. Soukoulis, K. Hingerl, M. Muehlberger, R. Schoeftner, Single and multilayer metamaterials fabricated by nanoimprint lithography. Nanotechnology 22, 325301 (2011)

140. X. Wang, A. Albrecht, H.H. Mai, C. Woidt, T. Meinl, M. Hornung, M. Bartels, H. Hillmer, High resolution 3D nanoimprint technology: template fabrication, application in FabryPérot-filter-array-based optical nanospectrometers. Microelectron. Eng. 110, 44-51 (2013)

141. L. Gao, K. Shigeta, A. Vazquez-Guardado, C.J. Progler, G.R. Bogart, J.A. Rogers, D. Chanda, Nanoimprinting techniques for large-area three-dimensional negative index metamaterials with operation in the visible and telecom bands. ACS Nano 8(6), 5535-5542 (2014)

142. R. Hensel, A. Finn, R. Helbig, H.-G. Braun, C. Neinhuis, W.-J. Fischer, C. Werner, Biologically inspired omniphobic surfaces by reverse imprint lithography. Adv. Mater. 26(13), 2029-2033 (2014)

143. W. Wu, M. Hu, F.S. Ou, Z.Y. Li, R.S. Williams, Cones fabricated by 3D nanoimprint lithography for highly sensitive surface enhanced Raman spectroscopy. Nanotechnology 21, 255502 (2010)

144. N. Gadegaard, K. Seunarine, D.J.A. Smith, D.O. Meredith, C.D.W. Wilkinson, M.O. Riehle, A hybrid three-dimensional nanofabrication method for producing vascular tissue engineering scaffold. Jpn. J. Appl. Phys. 47, 7415-7419 (2008)

145. I. Fernandez-Cuesta, A.L. Palmarelli, X. Liang, J. Zhang, S. Dhuey, D. Olynick, S. Cabrini, Fabrication of fluidic devices with $30 \mathrm{~nm}$ nanochannels by direct imprinting. J. Vac. Sci. Technol. B 29(6), 06F801-1/7 (2011)

146. A. Schleunitz, M. Vogler, I. Fernandez-Cuesta, H. Schift, G. Gruetzner, Innovative and tailor-made resist and working stamp materials for advancing NIL-based production technology. J. Photopolym. Sci. Technol. (Jpn.) 26(1), 119-124 (2013)

147. R. Kirchner, V.A. Guzenko, M. Rohn, E. Sonntag, M. Muehlberger, I. Bergmair, H. Schift, Bio-inspired 3D funnel structures made by grayscale electron-beam patterning and selective topography equilibration. Microelectron. Eng. 141, 107-111 (2015)

148. P. Urwyler, H. Schift, J. Gobrecht, O. Häfeli, M. Altana, F. Battiston, B. Müller, Surface patterned polymer micro-cantilever arrays for sensing. Sens. Actuators A 172(1), 2-8 (2011)

149. J. Söchtig, H. Schift, P.D. Patterson, S. Westenhöfer, Replicated diffractive optical lens components for laser-diode to fiber coupling in optical bench arrangements, in Proceedings of the SPIE 3226, (1997), pp. 44-55

150. T. Mäkelä, T. Haatainen, Roll-to-roll pilot nanoimprinting process for backlight devices. Microelectron. Eng. 97, 89-91 (2012)

151. T. Mäkelä, T. Haatainen, J. Ahopelto, Pilot production of photonic devices by roll-to-roll nanoimprinting. J. Photopolym. Sci. Technol. 25(2), 227-228 (2012)

152. C.M. Sotomayor-Torres, J. Ahopelto, Position Paper on Nanophotonics and Nanophononics, NanoICT. Phantoms Foundation, Madrid, Spain. http://www.phantomsnet.net/

153. Kindle Paperwhite, 6" High Resolution Display, Kindle Paperwhite-Released 2012, http://www.amazon.com/Kindle-Paper white-Touch-light/dp/B007OZNZG0. Accessed 12 Dec 2014

154. J. Hruska, ExtremeTech, Electronics, Amazon sheds new light on Kindle Paperwhite display, 1 Oct 2012, http://www.extre metech.com/electronics/137158-amazon-sheds-new-light-on-kin dle-paperwhite-display. Accessed 12 Dec 2014

155. The New York Times, Business Day Technology, Published: December 26, 2012, Light reading: how the Kindle Paperwhite works, http://www.nytimes.com/interactive/2012/12/26/technol ogy/light-reading.html. Accessed 12 Dec 2014

156. K. Rinko, Ultrathin Lighting Element, International Publication Number WO2005/107363 A2, priority date 30 April 2004

157. K. Rinko, Light Outcoupling Structure for a Lighting Device, International Publication Number WO 2008/053078 A1, 2006, priority date 31 October

158. T. Buß, J. Teisseire, S. Mazoyer, C.L.C. Smith, M.B. Mikkelsen, A. Kristensen, E. Søndergård, Controlled angular redirection of light via nanoimprinted disordered gratings. Appl. Opt. 52(4), 709-716 (2013)

159. S. Klammt, A. Neyer, H.F.O. Mueller, Microoptics for efficient redirection of sunlight. Appl. Opt. 51, 2051-2056 (2012)

160. H. Schift, C. Spreu, M. Saidani, M. Bednarzik, J. Gobrecht, A. Klukowska, F. Reuther, G. Gruetzner, H.H. Solak, Transparent hybrid polymer stamp copies with sub-50 nm resolution for thermal and UV-nanoimprint lithography. J. Vac. Sci. Technol. B 27(6), 2846-2849 (2009)

161. A. Schleunitz, C. Spreu, T. Haatainen, A. Klukowska, H. Schift, Fabrication of mesas with micro- and nanopatterned surface relief used as working stamps for step \& stamp imprint lithography. J. Vac. Sci. Technol. B 28(6), C6M37-C6M40 (2010)

162. T. Haatainen, T. Mäkelä, A. Schleunitz, G. Grenci, M. Tormen, Integration of rotated 3-D structures into pre-patterned PMMA substrate using step \& stamp nanoimprint lithography. Microelectron. Eng. 98, 180-183 (2012)

163. G. Grenci, E. Sovernigo, A.Z. Khokhar, N. Gadegaard, M. Prasciolu, M. Tormen, Microfabrication of sharp blazed gratings by a two-step height amplification process based on soft and deep X-ray lithography. Sens. Actuators A 205, 111-118 (2014)

164. M. Li, L. Chen, S.Y. Chou, Direct three-dimensional patterning using nanoimprint lithography. Appl. Phys. Lett. 78(21), 3322-3324 (2001)

165. P. Batude, M. Vinet, B. Previtali, C. Tabone, C. Xu, J. Mazurier, O. Weber, F. Andrieu, L. Tosti, L. Brevard, B. Sklenard, P. Coudrain, S. Bobba, H. Ben Jamaa, P-E. Gaillardon, A. Pouydebasque, O. Thomas, C. Le Royer, J.-M. Hartmann, L. Sanchez, L. Baud, V. Carron, L. Clavelier, G. De Micheli, S. Deleonibus, O. Faynot, T. Poiroux, Advances, challenges and opportunities in 3D CMOS sequential integration, in IEEE Electron Devices Meeting (IEDM) (2011)

166. Z. Liu, D.G. Bucknall, M.G. Allen, Inclined nanoimprinting lithography for 3D nanopatterning. Nanotechnology 22, 225302 (2011) 